AnUARIO DE Estudios MEdIEVALES

46/2, julio-diciembre de 2016, pp. 859-898

ISSN 0066-5061

doi:10.3989/aem.2016.46.2.09

\title{
COMUNIDADES LOCALES, LUGARES CENTRALES Y ESPACIOS FUNERARIOS EN LA EXTREMADURA DEL DUERO ALTOMEDIEVAL: LAS NECRÓPOLIS DE TUMBAS EXCAVADAS EN LA ROCA ALINEADAS ${ }^{1}$
}

\section{LOCAL COMMUNITIES, CENTRAL PLACES AND BURIAL AREAS IN EARLY MEDIEVAL EXTREMADURA OF THE RIVER DUERO: THE ROW-ORGANIZED CEMETERIES OF ROCK-CUT GRAVES}

\author{
IÑAKI MARTÍN VISO \\ Universidad de Salamanca
}

\begin{abstract}
Resumen: El trabajo se centra en el análisis de un tipo específico de espacios funerarios: las necrópolis de tumbas excavadas en roca alineadas. Se trata de una organización de las áreas de inhumación completamente diferente a los modelos predominantes y se vincula a una memoria comunitaria y jerarquizada. $\mathrm{Su}$ presencia se detecta en buena parte de los "lugares centrales" que sirvieron para la integración de la región al sur del Duero en la monarquía asturleonesa en el siglo X. Por consiguiente, se plantea que fueran el resultado de las transformaciones provocadas por ese proceso dentro de las comunidades que vivían en tales "lugares centrales". Finalmente, la implementación de una red eclesiástica a partir de finales del siglo XI conllevó la construcción de parroquias sobre estas necrópolis y un cambio en la memoria y la identidad comunitarias.
\end{abstract}

\begin{abstract}
This work focusses on the analysis of a particular type of burial areas: the row-organized cemeteries of cut rock-graves. The layout of this pattern was very different than those of the majority of the contemporary burial areas and it was related to a communitarian and hierarchical memory. The row-organized cemeteries were situated in some "central places" integrated into the south of the valley of river Duero during the tenth century. Therefore, that socio-political process involved some important transformations inside the local communities of the "central places", and this kind of burial area was a part of these transformations. Finally, the shaping of the parish system from the end of eleventh century onwards changed the communitarian memory and identity mirrored in the construction of churches over row-organised cemeteries.
\end{abstract}

\footnotetext{
${ }^{1}$ Este trabajo se ha realizado dentro del marco del proyecto de investigación Territorio e identidades locales en el centro de la Península Ibérica altomedieval: análisis espacial de las tumbas excavadas en la roca (HAR2010-21950-C03-02). Quiero agradecer los datos e informaciones proporcionados por Ángel Palominos (Aratikos Arqueólogos S.L.), Javier Quintana (Alacet Arqueólogos), Fernando Pérez-Rodríguez Aragón (Museo de Valladolid), Maria do Ceu Ferreira (Câmara Municipal de Trancoso) y Catarina Tente (Universidade Nova de Lisboa).
} 
Palabras clave: necrópolis; lugares centrales; integración política; Alta Edad Media; memoria; comunidades locales.
Keywords: cemeteries; central places; political integration; early Middle Ages; memory; local communities.

\section{SUMARIO}

1. Las tumbas excavadas en la roca y su análisis.- 2. Las necrópolis alineadas en la Extremadura del Duero.- 3. Los datos del registro escrito: la integración política del siglo X.- 4. Cruzando datos: identidades locales en transformación.- 5. Bibliografía citada.

\section{LAS TUMBAS EXCAVADAS EN LA ROCA Y SU ANÁLISIS}

Los estudios sobre la Extremadura del Duero han demostrado el papel desempeñado por los sistemas políticos concejiles como ejes vertebradores de toda esta zona desde el siglo XII en adelante ${ }^{2}$. Pero el periodo altomedieval sigue siendo poco conocido. La aportación más sólida la constituyen los estudios sobre toponimia de Ángel Barrios, realizados en los años 80 del siglo pasado ${ }^{3}$. Partiendo del estudio de los nombres de lugar recogidos en extensas listas de parroquias de los obispados de la zona datadas a mediados del siglo XIII, este historiador pudo observar la permanencia de topónimos prerromanos, romanos, germánicos y árabo-beréberes que demostrarían que se mantuvo un sustrato poblacional a lo largo de los siglos altomedievales, contradiciendo así la teoría de la despoblación del valle del Duero. Por otro lado, la llegada de gentes externas, campesinos procedentes del norte, en un movimiento espontáneo, habría dinamizado la sociedad al sur del Duero, lo que, unido a la implantación del poder regio a finales del XI, habría dado como resultado la génesis de los concejos. Esta teoría se basa en un análisis magistral de la toponimia, pero no está exenta de serios problemas. El primero de ellos es el tipo de evidencia que se utiliza, la toponimia, cuya evolución responde a dinámicas sociales complejas y no es un puro reflejo de la procedencia de una población residente ${ }^{4}$. Por otro lado, la necesidad de criticar la

2 Entre los estudios más destacados, estarían Barrios 1983-1984; Villar 1986; Monsalvo 1992, 2003.

${ }^{3}$ Barrios 1985.

${ }^{4}$ Por ejemplo, se ha planteado que la abundante toponimia anglo-sajona, frente a la exigua nómina romano-bretona, confinada al extremo occidental de Gran Bretaña, sería el resultado, no tanto de una sustitución de la población, como de la adopción de nuevos modelos culturales por parte de la población autóctona, Hooke 1997. 
teoría de la despoblación ${ }^{5}$ lastró la construcción de una explicación alternativa sólida. La colonización espontánea implicaba un movimiento generalizado y perdurable de gentes que se desplazaron al sur, una realidad que, sin embargo, no ha dejado otra huella más que la toponimia. La documentación escrita del norte peninsular no recoge ese movimiento, que conllevaba el abandono de tierras y de redes sociales donde estaba integrada la familia campesina, es decir un desarraigo radical. Por último, las teorías de la colonización -que renovaron los paradigmas explicativos y crearon una agenda de investigación que todavía hoy es válida- niegan la agencia social de las comunidades autóctonas, pues sólo el impulso externo sirvió como catalizador de los cambios.

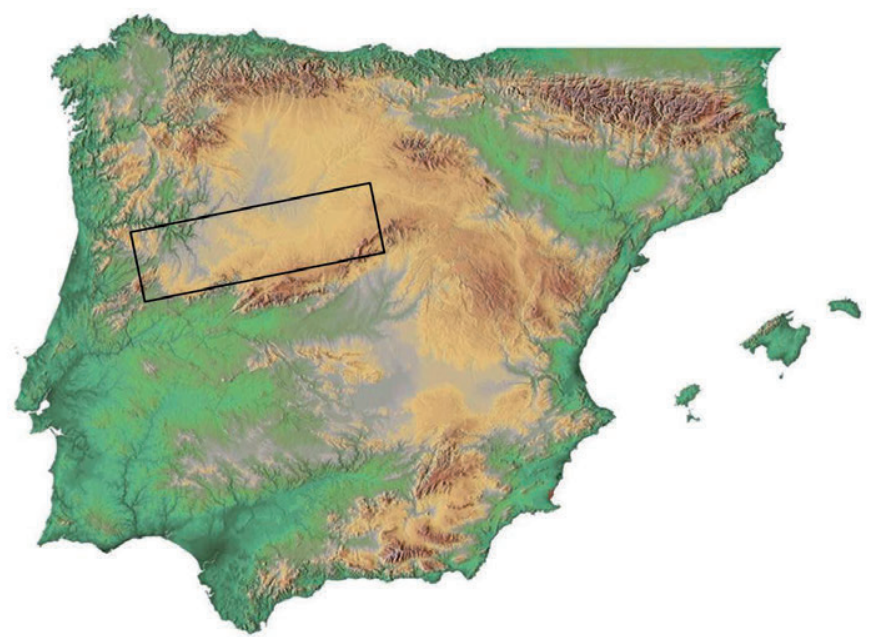

Fig. 1. Localización de la zona de estudio: la Extremadura del Duero.

Tales reflexiones no suponen minusvalorar unos trabajos que siguen siendo imprescindibles, sino entenderlos como puntos de partida ${ }^{6}$. En tal sentido, cabe señalar el escaso papel otorgado a la arqueología. Es cierto que a la altura de los años 80, la información era poca y de muy pobre calidad. Sin embargo, el incremento de la arqueología preventiva y la existencia de algunos proyectos específicos ofrecen evidencias cada vez mayores para ese periodo. Como consecuencia, disponemos de más datos sobre el periodo altomedieval,

\footnotetext{
${ }^{5}$ Sánchez-Albornoz 1966.

${ }^{6}$ Para el caso que nos ocupa, y dentro de esta perspectiva, deben verse los fundamentales trabajos de Mínguez 1997, 2007. 
aunque hace falta una lectura crítica de los mismos y una integración en marcos interpretativos que permitan conocer mejor los procesos sociales. La capacidad heurística del dato arqueológico es muy superior a la de la toponimia si se pretende estudiar tales procesos sociales, convirtiéndose en un registro imprescindible para conocer el paisaje y las formas de ocupación del territorio ${ }^{7}$. El reto es construir una arqueología capaz de ofrecer esas herramientas y de hacernos comprender cómo funcionaron y se transformaron unas sociedades sin estado.

La información sigue siendo parca y las dificultades son numerosas, pues aún no disponemos de un registro de calidad. Quizá el indicio más evidente, y también el mejor conservado, sean las tumbas excavadas en la roca, muy frecuentes en los terrenos paleozoicos que predominan en este sector. Se trata de sepulturas realizadas directamente en la roca, normalmente granito o pizarra, y que configuran áreas funerarias altomedievales. Aunque existen evidencias de otros modelos de tumbas (en cistas, de lajas), que incluso conviven en el mismo espacio con las tumbas excavadas en la roca $^{8}$, parece que el modelo estadísticamente predominante en el periodo altomedieval son las tumbas excavadas en la roca, mientras que los enterramientos en tumbas de lajas tuvieron una periodización más larga.

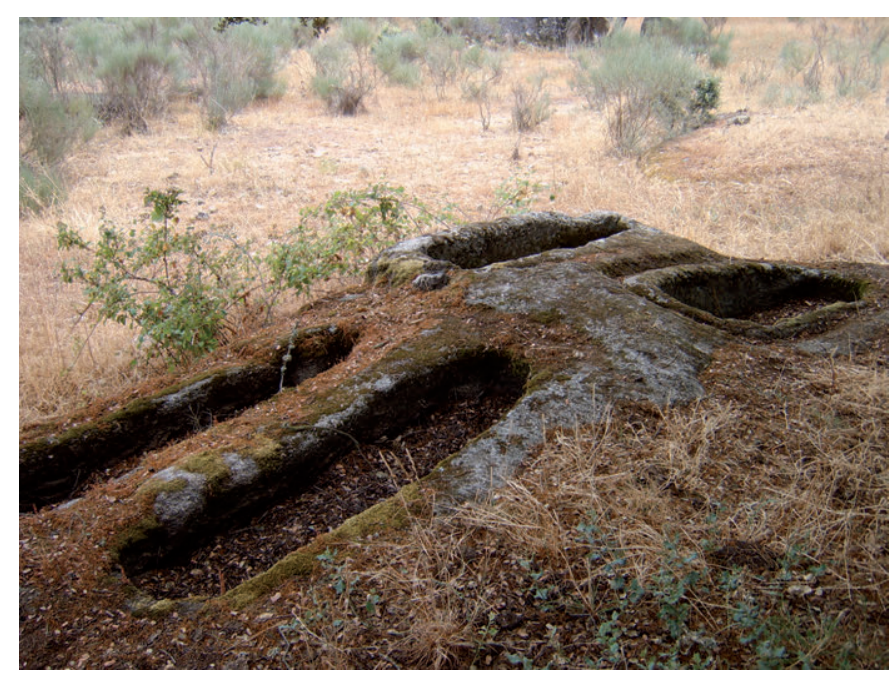

Fig. 2. Tumbas excavadas en la roca en Calleja Lagar (Villar de Ciervo, Salamanca).

\footnotetext{
2009.

${ }^{7}$ Para la zona que nos ocupa, veánse Tente 2007, 2011; Blanco, López Sáez, López Merino

${ }^{8}$ Martín Viso 2012a, pp. 21-22.
} 
Pero el análisis de este tipo de tumbas se enfrenta a serios problemas, en especial la ausencia de una cronología bien definida. En el caso de la región al sur del Duero, la mayoría de las sepulturas no han conservado ni restos óseos ni ajuares. Las tumbas, fácilmente visibles en el paisaje, aparecen ya vacías y, por tanto, los posibles depósitos han quedado destruidos. A ello se añade la especial acidez de los suelos -en especial los graníticos, curiosamente aquellos en los que de manera preferente se emplazan las tumbas-, que dificulta la conservación de cualquier tipo de evidencia. Por otro lado, se sigue usando la cronotipología establecida en los años 60 del siglo XX por Alberto del Castillo, quien consideraba que las tumbas antropomórficas u "olerdolanas" correspondían a la repoblación mozárabe que habría tenido lugar en los siglos IX y X y, por tanto, eran posteriores a las no-antropomorfas, que se habrían comenzado a elaborar a finales del VII ${ }^{9}$. El razonamiento se basaba en consideraciones formales - una secuencia de formas aparentemente menos elaboradas a otras más elaboradas- y delataba una gran dependencia de las explicaciones procedentes del registro escrito, en especial del modelo despoblacionista. Sin embargo, la cronotipología de Alberto del Castillo se ha convertido en una suerte de paradigma que sigue manteniéndose, a pesar de la fragilidad de los argumentos ${ }^{10}$.

No obstante, en los últimos años se han proporcionado algunas dataciones absolutas, a partir de restos óseos. Un aspecto destacable es la existencia de una horquilla de dataciones que se mueve entre los siglos VII al XI, con fuertes diferencias regionales ${ }^{11}$. En el caso que nos ocupa, resulta particularmente interesante la datación de un pequeño fragmento óseo procedente del lugar de Alto da Quintinha (Fornos de Algodres, Portugal), que ha proporcionado una datación del siglo $\mathrm{X}^{12}$. De todos modos, hay que tener en cuenta que la intensa reutilización de estas tumbas implica que las dataciones pueden estar marcando los momentos finales de utilización, marginando los primeros enterramientos. Por otra parte, algunos datos indirectos han permitido plantear una cronología al menos aproximada. Así, la presencia de ciertos ajuares permite plantear una secuencia inicial de las tumbas en el siglo VII e incluso anterior $^{13}$. Ahora bien, el hecho de que a partir de esa centuria, la presencia de

\footnotetext{
${ }^{9}$ Castillo 1970, 1972. Esta explicación, aunque con matices, fue asumida por algunas discípulas de Alberto del Castillo, Loyola 1977; Bielsa 1977; Andrio 1994. Véase también Padilla, Álvaro 2012.

${ }^{10}$ Fortó, Maese, Vidal 2012.

${ }^{11}$ Benavente, Paz, Ortiz 2006; Ajamil 2012; Ollich, 2012; Molist, Bosch, 2012.

${ }^{12}$ Tente, Carvalho 2011, pp. 466-467, con una datación 840-1040 AD calibrada a $2 \sigma$.

${ }_{13}$ Domenech 1994; Gutiérrez Dohijo 2001; Mora-Figueroa 1981; Ruiz Cecilia, Román 2005; Varela 2002.
} 
ajuares en las sepulturas de toda Europa Occidental desaparezca ${ }^{14}$, implica de nuevo que buena parte de la evidencia, en especial los enterramientos posteriores, sin ajuares, quedan oscurecidos. En zonas meridionales de la Península Ibérica, estaríamos ante inhumaciones previas a los procesos de islamización, fechables a partir del siglo IX, o incluso podrían ser una huella de poblaciones cristianas que se mantuvieron en al-Andalus ${ }^{15}$. Volviendo a nuestro ámbito de estudio, en el yacimiento de São Gens (Forno Telheiro, concelho de Celorico da Beira), se ha podido detectar la existencia de un asentamiento dotado de una pequeña muralla y fechado entre los siglos IX y X, que parece estar asociado a la cercana necrópolis de tumbas excavadas en la roca, que respeta el área residencial, por lo que parece tratarse de dos elementos vinculados entre $\mathrm{si}^{16}$. Pero esa datación choca con los datos preliminares del yacimiento de La Genestosa (Casillas de Flores, Salamanca), donde las tumbas excavadas en la roca se encuentra asociadas a algunas estructuras que estuvieron en uso al menos entre los siglos V y VII ${ }^{17}$.

La disparidad cronológica, aunque siempre en un marco entre los siglos VII al XI, se debe a que no estamos ante una realidad homogénea. La extraordinaria difusión del fenómeno por numerosas regiones de la Península Ibérica, e incluso en zonas de la actual Francia ${ }^{18}$, y su presencia en contextos muy diferentes, son factores que no han de obviarse. En realidad, estamos ante una forma de enterramiento que se aplica a contextos muy distintos, que van desde remotas áreas rurales a inhumaciones ad sanctos en un entorno episcopal y urbano ${ }^{19}$. Plantear el fenómeno en términos únicos -regionales y/o funcionale ${ }^{20}$ - supone un error metodológico.

Una forma de superar el impasse sobre el estudio de estas tumbas es analizarlas como una parte integral de un paisaje. Algunos estudios en Portugal han utilizado a las tumbas excavadas en la roca como una evidencia para detectar el poblamiento rural altomedieval, de carácter disperso ${ }^{21}$. Sin embargo, esta ecuación no parece tan sencilla, ya que pueden existir aldeas que no dispongan de espacios centralizados de inhumación. En realidad, lo que vemos es la ausencia de un fuerte control de la elección de los lugares de enterramiento $\mathrm{y}$, por ende, de las prácticas rituales, pero eso no significa automáticamente

\footnotetext{
${ }^{14}$ Para comprender este fenómeno, véase La Rocca 1989.

${ }^{15}$ Serrano, Castillo 2000; Jiménez, Mattei, Ruiz Jiménez 2011.

${ }^{16}$ Tente 2009, pp. 148-149; 2010, pp. 203-266.

${ }^{17}$ Martín Viso, Rubio 2013.

${ }^{18}$ Collardelle, Démians d'Archimbaud, Raynaud 1996; Durand 1988, pp. 102 y 163.

${ }^{19}$ Como sucede con las tumbas excavadas en roca situadas junto a la basílica de El Tolmo de Minateda y datadas por carbono 14 en el siglo VII; Gutiérrez Lloret, Cánovas 2009, p. 100.

${ }^{20}$ López Quiroga 2010, pp. 302-359.

${ }^{21}$ Barroca 1987, pp. 128-129; Marques 2000a; Vieira 2004; Tente 2007; Lourenço 2007.
} 
un hábitat disperso ${ }^{22}$. Pero se han abierto otras vías de explicación sobre las tumbas excavadas en roca. Así, los trabajos sobre el valle del río Martín han permitido datar algunos de los conjuntos de tumbas excavadas en la roca en el siglo VII, al mismo tiempo que se relacionarían con un emplazamiento que busca el dominio visual de las áreas de cultivo, que determinarían la localización de estas tumbas ${ }^{23}$. En el sur del Duero, algunos recientes estudios sobre la comarca portuguesa de Riba Côa y el entorno de Ciudad Rodrigo, en Salamanca, han planteado el papel de las tumbas como auténticos marcadores del paisaje, en relación posiblemente con la reclamación de derechos sobre determinadas tierras ${ }^{24}$. Estos estudios, junto con el replanteamiento de la interpretación que se está haciendo desde los paradigmas tradicionales ${ }^{25}$, se encaminan hacia la renovación del análisis de las tumbas excavadas en la roca.

Se trata de comprender el papel de los espacios funerarios dentro de un paisaje, y sobre todo dentro de la construcción simbólica de ese paisaje como un escenario en el que se mueve la identidad individual y colectiva. Un paisaje que funciona como una fuente de referencia y un contexto dotado de significado social y cultural ${ }^{26}$. El paisaje se convierte en una arena privilegiada para la construcción de la memoria y de la identidad, una construcción en la que ni es un mero espejo de procesos externos, ya que resulta ser parte activa, ni es un resultado fijo y estable, sino que los mismos paisajes son vividos y conceptualizados de formas diferentes por los individuos, los grupos sociales y las instituciones ${ }^{27}$. Este concepto de paisaje permite integrar más adecuadamente a las necrópolis, que son el resultado de una decisión deliberada para designar una porción de tierra como área destinada al enterramiento ${ }^{28}$. De esta forma, las necrópolis pueden ser vistas como lugares y herramientas de una memoria que forja vínculos entre gentes, redes sociales y la tierra ${ }^{29}$, gracias al recuerdo de los ancestros ${ }^{30}$. Y es que los cementerios o las áreas funerarias no son la consecuencia "natural" de la muerte sino el resultado de la agencia humana, de decisiones sociales entendidas en sus contextos históricos. Funcionan como lugares de recuerdo, donde el pasado y el

${ }^{22}$ Martín Viso 2009, pp. 125-126.

${ }^{23}$ Laliena, Ortega 2005.

${ }^{24}$ Martín Viso 2007, 2012b; Rubio 2011.

${ }^{25}$ Padilla, Álvaro 2010.

${ }^{26}$ Escalona 2010, p. 64; David, Thomas 2008, pp. 27-45.

${ }^{27}$ Knapp, Ashmore 2000.

${ }^{28}$ Härke 2001, p. 12.

${ }^{29}$ Williams 2003.

${ }^{30}$ Devlin 2007,p. 49. Esto implica que las necrópolis y tumbas son puntos de referencia para la construcción de una memoria del pasado y, por tanto, son una parte activa en esa memoria, Van Dyke, Alcock 2003. 
presente se conectan ${ }^{31}$. De esta manera, forman parte de una memoria social que, en el caso de los campesinos medievales, tiene un referente esencial en la geografía local ${ }^{32}$.

Atendiendo a estos criterios de diversidad y de una función asociada a la memoria social, se ha planteado una tipología de alcance exclusivamente regional. Se trata, en definitiva, de observar la existencia de una abigarrada "geografía funeraria", en la que pueden convivir distintos tipos de espacios de enterramiento ${ }^{33}$. Existirían tres grandes patrones ${ }^{34}$. El primero y más frecuente sería el compuesto por tumbas aisladas o formando pequeños grupos, inferiores en todo caso a las 10 tumbas. Se trata de la tipología más frecuente, tal y como se observa en distintos estudios sobre comarcas específicas de la región ${ }^{35}$. Pero además es un patrón muy común también en otras zonas de Europa Occidental, donde la mayoría de los espacios funerarios de los siglos VII al XI se caracterizarían por ser tumbas aisladas, en muchas ocasiones localizadas en las inmediaciones de las áreas residenciales o dentro de ellas ${ }^{36}$. Las tumbas aisladas de la región al sur del Duero se sitúan preferentemente cerca de los pequeños cursos fluviales que se abren camino entre terrenos paleozoicos, muy ácidos y de escasa capacidad agropecuaria y que constituyen las principales áreas de producción. La elección de rocas graníticas, muchas de ellas emplazadas en posiciones relevantes dentro del paisaje, resulta relevante, ya que reforzarían el carácter "monumental" de estas sepulturas y, con ello, su función social. Podría tratarse de monumentos campesinos asociados a la reclamación de derechos de propiedad, que pueden ser vistos por las gentes que habitan en el paisaje. En tal caso, hay que señalar que solo algunas personas debieron tener acceso a este tipo de inhumación, que, por sus características, parece que era costoso. Podrían entenderse como monumentos campesinos erigidos por algunos miembros de familias relevantes, que recordaban a un ancestro igualmente prestigioso. Todo ello estructura un paisaje en el que no se puede hablar de zonas de enterramiento perfectamente definidas.

${ }^{31}$ Williams 2006, p. 197.

${ }^{32}$ Fentress, Wickham 2003, p. 141.

${ }^{33}$ Williams 2006, p. 191.

${ }^{34}$ Martín Viso 2012b.

${ }^{35}$ Fabián et al. 1986; Marques 2000a, pp. 186-187; Vieira 2004, p. 74; Tente 2007, p. 93; Lourenço 2007, pp. 33 y 61; Martín Viso 2007.

${ }^{36}$ Sin ánimo de exhaustividad, veánse Pecqueur 2003; Zadora-Rio 2005, pp. 18-19; Blaizot 2006; Hamerow 2012, pp. 127-129. 


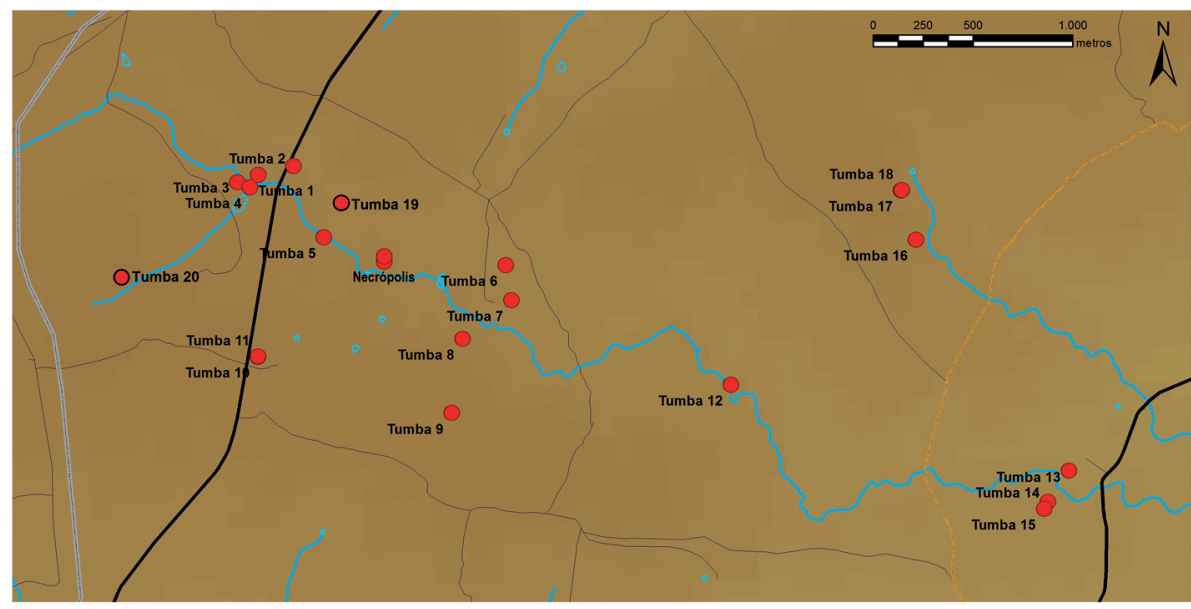

Fig. 3. Un modelo de tumbas aisladas: el caso del arroyo del Mazo de Prado Álvaro (Casillas de Flores, Salamanca).

El segundo patrón corresponde a las necrópolis rurales desordenadas, espacios funerarios con más de 10 enterramientos, articulados como áreas en las que se distribuyen de manera aparentemente aleatoria las tumbas de forma aislada y/o formando pequeños núcleos. Esta distribución posiblemente sea consecuencia de que la elección concreta de cada lugar de enterramiento fuera una decisión familiar y/o individual, aunque dentro de un espacio específico reconocido por un conjunto social más amplio. Parece factible pensar que se trataría de un tipo de escenario en el que hay comunidades que han segregado este espacio para la inhumación, aunque no hay estructuras de poder que organicen directamente la gestión de la necrópolis. Quizá estemos ante una memoria enraizada en la creación de un territorio apropiado por una comunidad, aunque esta se articule en familias, y tal vez el emplazamiento responda al dominio de áreas de especial interés o de control comunitario o simplemente de alto contenido simbólico, por su relación con un asentamiento cercano. Pero tampoco puede descartarse la posibilidad de que estemos ante espacios funerarios compartidos por varios asentamientos, dentro de una identidad supralocal, sobre todo cuando se sitúan en localizaciones relacionadas con zonas muy específicas de aprovechamiento ${ }^{37}$.

${ }^{37}$ Un ejemplo sería la necrópolis de La Coba (San Juan del Olmo, Ávila), compuesta por 81 tumbas distribuidas en un área de 20 has, y donde hay vestigios de 5 estructuras, un asentamiento muy reducido para tan alto número de tumbas en un territorio relativamente extenso. La ausencia de otros sitios con tumbas excavadas en la roca en sus cercanías, permite plantear la 


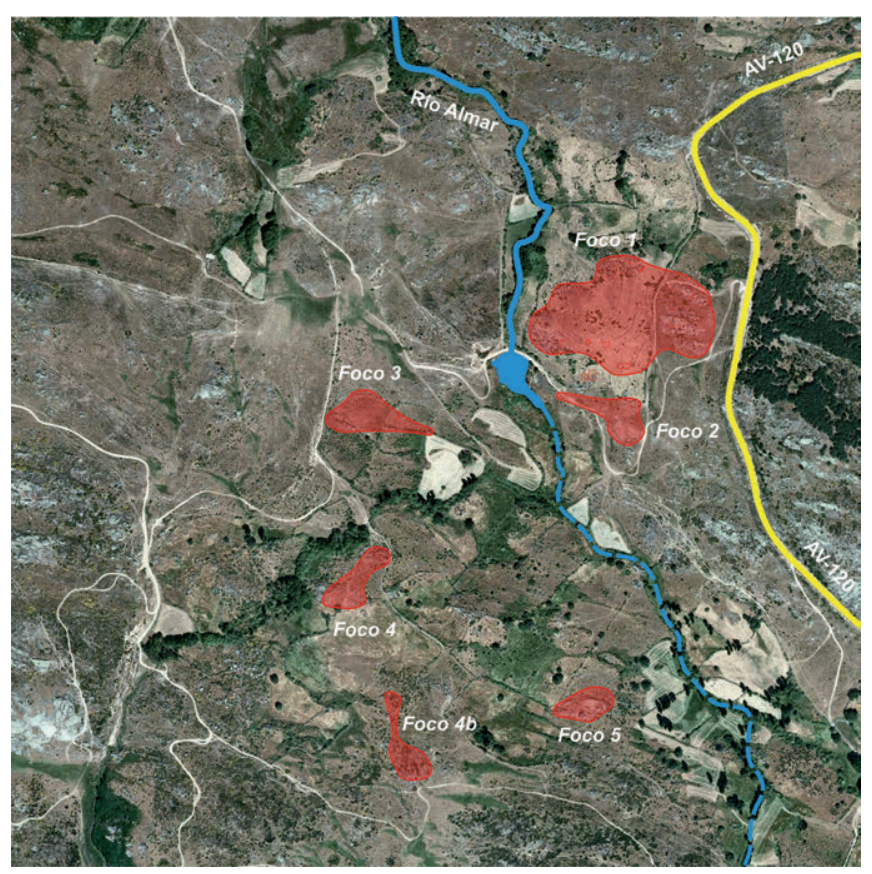

Fig. 4. Un modelo de necrópolis rural desordenada: el caso de La Coba (San Juan del Olmo, Ávila). Imagen creada por ortofoto (Castellum S. Coop.).

El último tipo sería el de las necrópolis de tumbas agrupadas y alineadas. En este caso, hablaríamos de necrópolis (más de 10 tumbas), en las que se detecta una clara agrupación de todas las tumbas -sin que haya núcleos aislados bien definidos-, las cuales se encuentran alineadas, con una tendencia hacia una orientación común Este-Oeste. Este patrón es el menos frecuente entre los yacimientos con tumbas excavadas en roca de la región de estudio. Porcentualmente, su presencia es marginal, pero su particular organización interna, diferente a las tumbas aisladas y a las necrópolis rurales desordenadas, implica que su significado en la construcción del paisaje es muy distinto. No se trata tanto de que la disposición alineada y agrupada tenga en sí mismo un sentido -pues es un patrón muy frecuente en otros ámbitos-, sino que cobra relevancia como factor diferenciador en un contexto funerario dominado por las

hipótesis de que en La Coba se concentraron las inhumaciones de varias de estas comunidades. Una razón que explicaría esa elección es que estamos ante un lugar de pastos críticos, en un área elevada, por lo que podría haber sido objeto de rutas transterminantes. 
tumbas aisladas y por las necrópolis rurales desordenadas ${ }^{38}$. Estaríamos ante un paisaje jerarquizado, en el que hay una memoria de la comunidad controlada y gestionada por esta o por una instancia de poder, salida de la comunidad o externa a ella, que ha eliminado la capacidad de gestión de la memoria familiar.

\section{LAS NECRÓPOLIS ALINEADAS EN LA EXTREMADURA DEL DUERO}

A partir de una revisión de los datos publicados e informaciones procedentes de intervenciones arqueológicas aún inéditas, se han podido identificar una serie de sitios de este tipo entre Sepúlveda y Viseu, aunque el listado no es definitivo. Son los casos de Ciudad Rodrigo (San Pelayo) ${ }^{39}$, Cuéllar (San Andrés, San Esteban y Santiago), Fuentidueña (San Martín), Ledesma (Santa Elena), Longroiva (Nossa Senhora do Torrão), Marialva (São Pedro y São João), Moreira de Rei (Santa Marina), Numão (S.Pedro y Santa Maria), Sacramenia (San Miguel), Salamanca (Universidad Pontificia), Sepúlveda (San Salvador y Santiago) y Trancoso (Tribunal). No todas las necrópolis se conocen en su totalidad, debido a que su localización dentro de los cascos urbanos actuales ha provocado un intenso uso de esos espacios, por lo que algunas de ellas han sido destruidas o amortizadas por edificios posteriores. Así sucede en Santiago (Cuéllar, Segovia), Nossa Senhora do Torrão (Longroiva, concelho de Mêda) ${ }^{40}$, São João (Marialva, concelho de Mêda), Santa Maria (Numão, concelho de Vila Nova de Foz Côa), San Salvador (Sepúlveda, Segovia) y Tribunal (Trancoso, concelho de Trancoso). En otras ocasiones, las intervenciones efectuadas se han limitado a pequeñas catas, que han puesto de relieve la presencia de esas tumbas, aunque sólo se conoce muy parcialmente el espacio funerario, como ocurre en Santa Elena (Ledesma, Salamanca) o en Santiago (Sepúlveda). De todas formas, todas las necrópolis presentan las características de una clara alineación de las tumbas, que se encuentran agrupadas, incluso cuando únicamente se observan fragmentos de esas necrópolis. De hecho, allí donde ha sido posible, se ha documentado la superposición de tumbas, síntoma inequívoco de una intensa utilización del espacio funerario ${ }^{41}$.

\footnotetext{
${ }^{38}$ Siguiendo los patrones establecidos por Parker 1999, p. 12, las tumbas aisladas y las necrópolis desordenadas responderían a un tipo de organización del espacio funerario segmentado, frente al lineal de las necrópolis alineadas.

${ }^{39}$ Sobre la identificación y análisis de este lugar, véase Martín Viso 2012b, pp. 181-183.

${ }^{40} \mathrm{Se}$ trata de un caso ejemplar, ya que en las inmediaciones de la capilla se encuentran seis sepulturas excavadas en la roca, dos de las cuales estarían en la parte trasera, actualmente soterradas, pero muchas otras habrían quedado afectadas por los grandes daños ocasionados por las obras de construcción de la capilla y el atrio, Antunes, Faria, Almeida 1998, pp. 243-245.

${ }^{41}$ Es lo que sucede en San Andrés (Cuéllar), Aratikos 2005, pp. 31, 34, 41.
} 


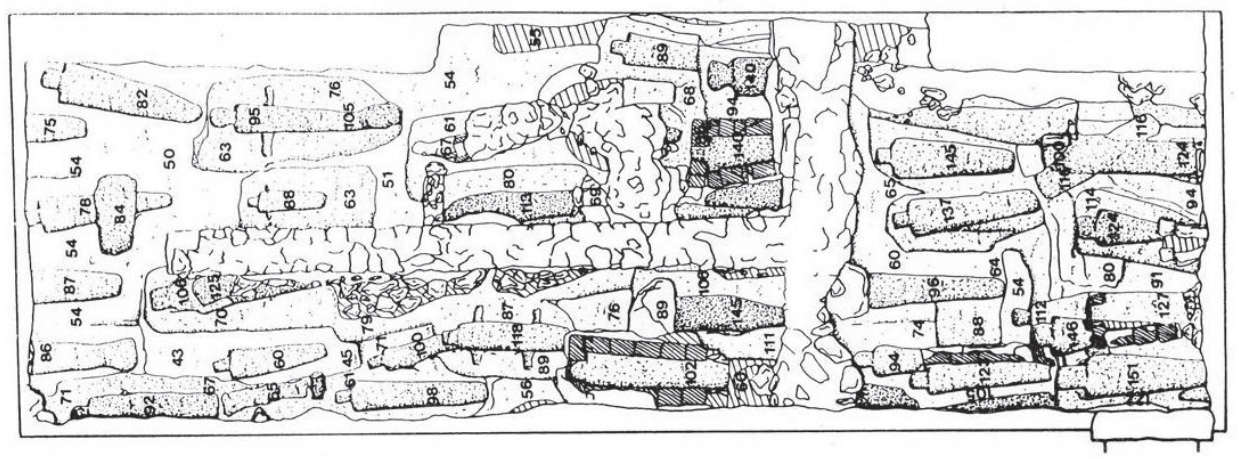

Fig. 5. Fragmento de una necrópolis alineada: San Andrés (Cuéllar). Imagen de Javier Arias, 1993, p. 234.

Los datos referidos al número de inhumaciones documentado también reflejan una considerable diferencia con respecto a lo que sucede en las tumbas aisladas. Cuando disponemos de visiones más o menos completas de los espacios funerarios, estos se mueven en una horquilla superior a las 50 inhumaciones, destacando el caso de San Martín, en Fuentidueña (Segovia) con 137 enterramientos ${ }^{42}$. Resulta muy probable que en otras necrópolis el número de tumbas fuera mayor, bien porque las iglesias actuales amortizan parte del espacio funerario, como ocurre por ejemplo en Santa Marina (Moreira de Rei, concelho de Trancoso) ${ }^{43}$, bien por la destrucción parcial de tumbas o simplemente porque la necrópolis se extendía más allá de la superficie excavada, como ocurre en la Universidad Pontificia (Salamanca). Por otro lado, debe tenerse en cuenta que algunas de estas necrópolis, aunque estén compuestas mayoritariamente por tumbas excavadas en la roca, presentan también otros formatos de sepulturas, como tumbas de fosa y de lajas ${ }^{44}$, lo que de alguna manera viene a relativizar la definición de estas necrópolis: el aspecto diferencial no es tanto el uso de las tumbas excavadas en roca, como su organización alineada. Otro aspecto relevante es la presencia de tumbas infantiles en muchas de estas necrópolis, aunque casi siempre en un número bajo. En San Miguel (Sacramenia, Segovia), 12 de las 62 tumbas documen-

${ }^{42}$ Golvano 1977.

${ }^{43}$ Ferreira 2000, p. 367.

${ }^{44}$ Es el caso de San Andrés (Cuéllar), donde se detectaron un total de 51 tumbas, de las cuales son antropomorfas talladas en la roca 39 ; del resto tenemos 7 en fosa y 4 hechas con ladrillo y mortero de cal, Arias 1993. 
tadas son infantiles ${ }^{45}$ y en la Universidad Pontificia (Salamanca) se conocen 14 tumbas sobre un total de $64^{46}$. En otros casos, el número no está bien determinado, pero, sin duda es bajo, como sucede en São Pedro (Marialva) ${ }^{47}$. No obstante, llama la atención que incluso cuando disponemos únicamente de pequeños fragmentos de esos espacios funerarios, aparecen tumbas infantiles, como sucede en Santa Elena (Ledesma) ${ }^{48}$. Se trata de un elemento que igualmente diferencia estas necrópolis, ya que en el caso de las tumbas aisladas y de las necrópolis rurales desordenadas prácticamente no se documentan este tipo de enterramientos.

Estos espacios funerarios se localizan en áreas extramuros, al menos hasta la construcción de las cercas plenomedievales. Cuando se puede rastrear esas fortificaciones anteriores a los siglos XII-XIII, se observa cómo las necrópolis alineadas se emplazan fuera del recinto, pero muy cerca de él, posiblemente en las inmediaciones de ciertas entradas, un modelo que recuerda al de las ciudades romanas. En Numão, la necrópolis de São Pedro se encuentra claramente extramuros, pero la de Santa Maria se halla dentro del perímetro fortificado del siglo XII ${ }^{49}$. Sin embargo, hay dos tumbas amortizadas en la muralla, posiblemente por la ampliación del recinto defensivo en época plenomedieval ${ }^{50}$. E igualmente significativo es el caso de San Miguel (Sacramenia), donde se ha detectado un muro justo en el extremo de cerro, que parece corresponder a una fortificación, anterior a la villa plenomedieval, situada a los pies del cerro, emplazándose la necrópolis fuera de esa posible muralla, aunque en un punto inmediatamente adyacente ${ }^{51}$. También en Salamanca, la muralla inicial, de origen romano, anterior a la expansión urbana de los siglos XII-XIII, se encuentra muy cerca de la necrópolis ${ }^{52}$. En otras ocasiones, la situación de estas necrópolis es claramente extramuros incluso en la actualidad, como sucede en Santa Elena (Ledesma), San Martín (Fuentidueña), Santa Marina (Moreira de Rei) o São Pedro (Marialva). Así, la necrópolis de San Pelayo (Ciudad Rodrigo, Salamanca) se hallaba extramuros del recinto amurallado primitivo, de los siglos XII-XIII, del que distaba tan solo unos 50 metros, en un emplazamiento que quizá se vincule a una

${ }^{45}$ Aratikos 2008, pp. 54-59.

${ }^{46}$ González Echegaray 2000, pp. 54-67.

${ }^{47}$ Amaral 2001, p. 133.

${ }^{48}$ Alacet 2006.

${ }^{49}$ Lopes, Valente, Barreira 1998.

${ }^{50}$ Martín Viso 2007, p. 29.

${ }^{51}$ Aratikos 2008, p. 48.

${ }^{52}$ González Echegaray 2000,pp. 43-50. 
vía de entrada y salida ${ }^{53}$. En Cuéllar, tanto San Andrés como San Esteban se emplazaban fuera del recinto amurallado ${ }^{54}$.

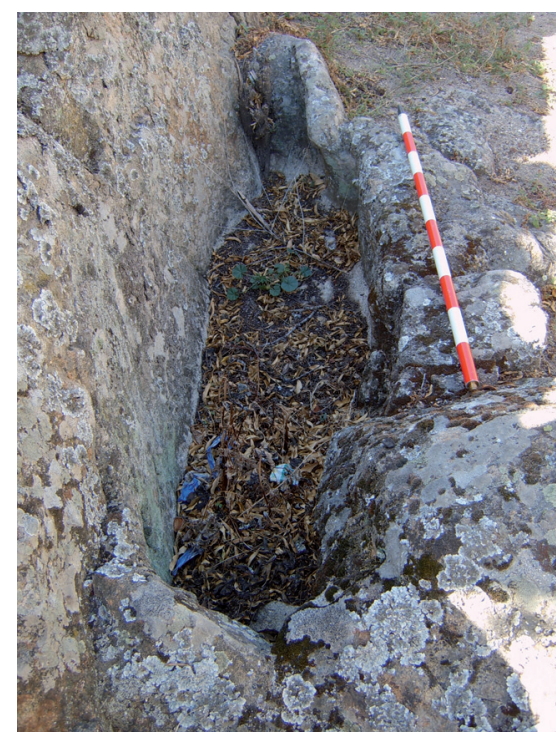

Fig. 6. Tumba excavada en roca amortizada por la muralla plenomedieval en Santa María de Numão.

Por otro lado, los estudios acerca de las tumbas excavadas en la roca se han fijado en la conexión entre centros de culto y espacios funerarios ${ }^{55}$. Sin embargo, los análisis arqueológicos llevados a cabo en los últimos años revelan cómo la configuración del cementerio parroquial es un fenómeno relativamente tardío, que no se generaliza hasta bien entrado el siglo $\mathrm{XI}^{56}$. Durante la Alta Edad Media, la mayoría de las áreas funerarias no se vinculaban a focos eclesiásticos, aunque todos los centros eclesiásticos dispusieron de sus propios espacios funerarios. Esta autonomía de áreas de inhumación con respecto a los centros de culto se explica porque la Iglesia no estuvo preocupada por los lugares de enterramiento, un aspecto reservado a decisiones de carácter familiar o comunitario. Fue la implementación de un programa reformista que reivindicaba el exclusi-

\footnotetext{
${ }^{53}$ Larrén, Gutiérrez González 1999; Viñé, Larrén 1996.

${ }^{54}$ En el caso de San Esteban, la intervención realizada ha permitido rechazar la hipótesis de que formara parte del recinto amurallado, pues no se ha hallado vestigio alguno de la cerca, Arroyo et al.2011, p. 34.

${ }^{55}$ López Quiroga 2010, pp. 334-351, donde se recoge por extenso esa opinión.

${ }^{56}$ Zadora-Rio 2003.
} 
vo papel mediador de la Iglesia entre el fiel y Dios y la configuración de espacios eclesiásticos sacralizados lo que posibilitó la progresiva y definitiva asociación entre parroquias y cementerios ${ }^{57}$. En el caso del Noroeste peninsular, el modelo parroquial y la nueva concepción de los espacios funerarios no se implementaron hasta los siglos XI y XII. Esto no impide que en algunas necrópolis de tumbas excavadas en la roca podamos encontrarnos con asociaciones con edificios eclesiásticos ${ }^{58}$.

En el caso de la región al sur del Duero, y tras eliminar supuestos vínculos basados en la presencia de micro-hagiotopónimos o de construcciones eclesiásticas posteriores al periodo de formación y uso de las áreas funerarias, se constata la ausencia de asociaciones entre sitios con tumbas excavadas en la roca y lugares eclesiásticos ${ }^{59}$. Ni siquiera se observa una posible relación con pequeñas edificaciones de tipo religioso, iglesias privadas o funerarias, como se ha detectado en otras zonas de Europa Occidental ${ }^{60}$. En cambio, las necrópolis alineadas muestran una clara vinculación con edificios eclesiásticos, casi todos ellos parroquias de las localidades en las que se encontraban. La única excepción es Tribunal (Trancoso), donde la parroquia de Santa Luzia, la más cercana, se encuentra lo suficientemente alejada como para no poder establecer una vinculación ${ }^{61}$.

Ahora bien, todas estas iglesias son posteriores al momento de formación de las necrópolis y no se han encontrado evidencias claras de estructuras eclesiásticas previas. En el caso de la Universidad Pontificia, la ausencia de evidencias de un centro de culto previo a la parroquia de San Pelayo ha obligado a datar a la necrópolis en los siglos XII-XIII, es decir en un momento bastante tardío con respecto a las cronologías aceptadas para este tipo de inhumaciones, como consecuencia de la necesidad de vincular espacio funerario con centro eclesiástico $^{62}$. A ello debe añadirse que en varios casos las zanjas de cimentación

\footnotetext{
${ }^{57}$ Treffort 1996; Lauwers 2005.

${ }^{58}$ Padilla 2002; Roig, Coll 2012. Una visión crítica con este planteamiento en Fortó, Maese, Vidal 2012.

${ }^{59}$ Martín Viso 2012a, pp. 15-16; Barroca 1987, p. 134.

${ }^{60}$ Parece que este sector no estuvo dotado de un gran número de iglesias hasta los siglos XI y XII, al menos en el medio rural. Se conocen muy pocos posibles testimonios de ese tipo de edificaciones y en general son casos muy dudosos, como Prazo (Freixo de Numão) o Las Vegas de Pedraza (Segovia). Véase Coixão 1999, pp. 54-124; Izquierdo 1977. Sobre estas iglesias y su relación con ámbitos funerarios antes de la implantación del sistema parroquial y normalmente con una posible vinculación a grupos aristocráticos, hay numerosos ejemplos, pero puede verse una interpretación en Zadora-Rio 2003.

${ }^{61}$ Agradezco a Maria do Ceu Ferreira sus informaciones acerca de esta parroquia y de su localización.

${ }^{62}$ González Echegaray 2000, p. 180. En San Esteban (Cuéllar), se postula la presencia de una iglesia previa, pero la intervención no ha ofrecido ningún dato al respecto, Aratikos 2005,
} 
e incluso los propios muros de las iglesias parroquiales, cuya construcción debe situarse entre los siglos XII y XIII, amortizan estructuras funerarias previas, lo que permite afirmar que las necrópolis no sólo eran previas, sino que las tumbas excavadas en la roca podrían haber dejado de prestar su función para la inhumación, como sucede en São Pedro (Marialva) o en San Miguel (Sacramenia) ${ }^{63}$. En Moreira de Rei, la iglesia de Santa Marina se erige sobre la necrópolis y la cimentación del edificio trajo consigo el rebaje de los bolos graníticos inmediatos, sobre los que se situaban las tumbas excavadas en roca. De hecho, las fases coetáneas a la construcción de los templos suelen caracterizarse por la existencia de tumbas de lajas o de ladrillos, muchas de ellas superpuestas a las fases previas, síntoma de la amortización y también de un uso intenso del área de inhumación ${ }^{64}$. Por último, la disposición de las tumbas, cubriendo sectores tanto en el interior como en el exterior de los edificios, con un diseño homogéneo, es decir, que no hay diferencias entre unas y otras, como si formasen un mismo grupo sobre el que se impone el edificio ${ }^{65}$, o el reaprovechamiento de materiales, como ocurre con un sarcófago monolítico, que se adosó al muro exterior sur de la iglesia de San Pelayo (Ciudad Rodrigo), son indicios de que las iglesias fueron un elemento posterior a los espacios funerarios ${ }^{66}$.

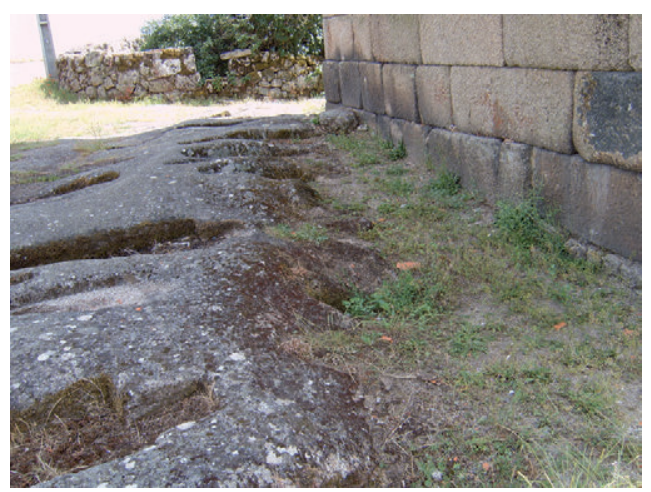

Fig. 7. La amortización de una necrópolis alineada por un edificio eclesiástico: el caso de Santa Marina (Moreira de Rei).

p. 54. Lo mismo sucede con Santa Elena (Ledesma), Alacet 2006. Tampoco en San Martín (Fuentidueña), se encontró el supuesto templo primitivo, Golvano 1977.

${ }^{63}$ Amaral 2001, p. 129; Aratikos 2008, p. 61. En Santa Elena (Ledesma), se afirma la contemporaneidad de la iglesia y la primera fase de la necrópolis, porque no se ha detectado que el muro de cimentación cubra las tumbas, pero eso puede deberse a que los sondeos no han sido muy extensos, Alacet 2006, pp. 82-83; Martín Viso 2011, p. 229.

${ }^{64}$ Buen ejemplo de ello es San Esteban (Cuéllar), Arroyo et al. 2011, p. 32.

${ }^{65}$ Como sucede en San Andrés (Cuéllar), Arias 1993, pp. 234-235.

${ }^{66}$ Viñé, Larrén 1996. 
Carecemos de una información clara acerca de las fechas exactas de la construcción de estos templos románicos, que fueron la manifestación arquitectónica de la implantación del nuevo sistema parroquial en estos lugares. Normalmente, la cronología se basa en aproximaciones efectuadas a partir del estudio de las facies estilísticas de los edificios o de la mención en los textos escritos de la existencia de tal o cual parroquia, indicios a todas luces inseguros. Sin embargo, en San Salvador (Sepúlveda), donde el templo se erige sobre un espacio funerario previo, se conserva en la base del ábside mayor una inscripción que parece fechar las obras de edificación del templo en $1093^{67}$. Aunque posiblemente sea una fecha muy temprana, que en otros casos podría llevarnos con mayor seguridad al siglo XII o principios del XIII, se trata de una evidencia que nos indica la amortización de la necrópolis. Esto no impide que pudieran darse casos de continuidad del espacio funerario tras la configuración de la iglesia parroquial, como ocurre en Marialva ${ }^{68}$. Incluso las evidencias numismáticas, como la presencia de monedas de la primera mitad del siglo XII en los inhumados de San Andrés (Cuéllar), nos estaría hablando de una perduración hasta ese momento $^{69}$. No obstante, la consolidación de la identidad parroquial supuso un cambio de significado social muy relevante.

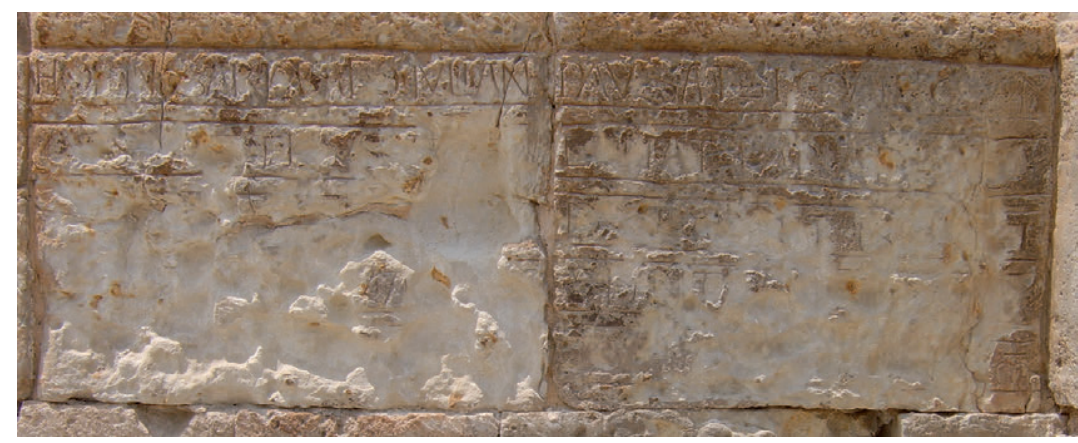

Fig. 8. Inscripción consacratoria procedente de la iglesia de Santiago (Sepúlveda) y fechada en 1093.

\footnotetext{
${ }^{67}$ Ruiz Montejo 1988, p. 17. La inscripción está muy deteriorada y únicamente se aprecia con claridad la data en la primera línea: "Era MCXXI".

${ }^{68}$ Aquí los análisis sobre restos óseos han permitido datar a un individuo en el siglo XV; Cunha, Umbelino, Tavares 2001. Sin embargo, se detecta un hiato temporal entre la fase bajomedieval y la inicial, que se ha datado en el siglo XII, sin que haya ninguna evidencia que así lo confirme, por lo que podría ser muy anterior, Amaral 2001, p. 129. Por tanto, puede existir un reaprovechamiento que no implica continuidad de uso.

${ }^{69}$ Arias 1993, p. 235. Dado que esta necrópolis muestra una fuerte reutilización de las tumbas, posiblemente las monedas daten el momento final de uso.
} 
En ese mismo sentido, cabe plantearse la cronología post quem de las necrópolis, pero nos enfrentamos a serios problemas ante la ausencia de dataciones absolutas, a pesar de que en algunos casos se han recuperado restos óseos. Nos movemos, por tanto, en un terreno lleno de conjeturas. El fenómeno de las necrópolis alineadas pudo ser o no sincrónico en todos los casos, pero llama la atención la existencia de una serie de rasgos específicos. Esta circunstancia permite plantear como hipótesis una datación más o menos común que quizá tenga su origen en un mismo proceso social. Sea como fuere, toda cronología referida a la formación de estas necrópolis y a su periodo de uso -teniendo siempre presente que lo que vemos es el resultado final de un espacio funerario dinámico y que debió utilizarse a lo largo de un periodo de tiempo más o menos dilatado- resulta de momento una pura conjetura. Por otra parte, el hecho de que se documenten varias de estas necrópolis en un mismo núcleo, como sucede en Numão, en Sepúlveda o en Cuéllar -pero también en Marialva ${ }^{70}$, puede interpretarse de dos maneras: o bien existieron sincrónicamente, por lo que la comunidad podía disponer de varios espacios de inhumación coetáneos, o bien se datarían en periodos diferentes.

Todos estos datos permiten plantear una hipótesis sobre ese significado social de las necrópolis alineadas, distinto al que poseían otros tipos de espacios funerarios. Parece posible explicar su presencia como la plasmación de una comunidad que se entierra en estos lugares, y que es la que toma la decisión de crear y gestionar esta zona para la inhumación, sin necesidad de intervención eclesiástica. La práctica ausencia de estelas en estas necrópolis nos hablaría de la inexistencia de marcadores propiamente individualizados o familiares fácilmente reconocibles. Por tanto, se trataría de un lugar de memoria asociado a una comunidad, donde el carácter monumental de las inhumaciones excavadas en roca-que puede defenderse en el caso de las tumbas aisladas- queda minimizado por el diseño del área funeraria. Esta función explicaría la presencia de tumbas infantiles, de las que no hay huellas en los otros tipos de espacios funerarios con tumbas excavadas en la roca, ya que en estos últimos el objetivo era mantener la memoria de un ancestro prestigioso, sin duda adulto. En cambio, en las necrópolis alineadas también los infantes tienen cabida en tanto en cuanto pertenecen a la comunidad que se representa y se perpetúa mediante estas áreas funerarias. Su emplazamiento en las inmediaciones de las posibles fortificaciones altomedievales parece indicar que se trataba de plasmar la relación entre el espacio funerario y su memoria con un determinado "lugar central", en definitiva con una comunidad política que tenía su huella en el paisaje a través de esas murallas. Una circunstancia muy

\footnotetext{
${ }^{70}$ Almeida, Antunes, Faria 2000, pp. 207-208; Dordio 1998, p. 34.
} 
diferente de la que se observa en las tumbas aisladas que se situaban cerca de espacios agroganaderos de interés local o incluso junto a áreas residenciales abiertas. Debe añadirse que la disposición interna alineada y agrupada podría responder a la existencia de una gestión efectuada por una fuerza que controla ese espacio funerario. Por tanto, sería la demostración de una comunidad jerarquizada, aunque no necesariamente desde un punto de vista eclesiástico.

\section{LOS DATOS DEL REGISTRO ESCRITO: LA INTEGRACIÓN POLÍTICA DEL SIGLO X}

En este punto, resulta interesante cruzar estos resultados con los procesos que pueden observarse a través del registro escrito. Sin embargo, hay que ser cuidadosos a la hora de llevar a cabo este ejercicio de cruce de registros, ya que ha sido frecuente la supeditación del dato arqueológico a las conclusiones inferidas desde la documentación escrita ${ }^{71}$. Se trata de plantear cómo procesos que se ven en una u otra esfera están interconectados entre sí, como si fueran caras diferentes de un proceso de más amplio calado.

A partir del siglo VIII, la zona al sur del Duero, al igual que buena parte del Noroeste peninsular, quedó al margen de cualquier estructura política centralizada. Al mismo tiempo, desapareció toda información escrita, lo que posiblemente deba interpretarse como un fuerte deterioro de las autoridades y elites que necesitaban de la escritura. La región al sur del Duero vuelve a aparecer en el registro escrito a partir del segundo tercio del siglo X, cuando tales territorios se integraron en las estructuras políticas cristianas del norte peninsular, a través de la "repoblación". Se trata de un proceso que afectó a casi toda la meseta del Duero a lo largo de la segunda mitad del siglo IX y la primera del X, con distintos gradientes. Conviene detenerse en un análisis de las pocas fuentes escritas que disponemos acerca de este proceso en la región que nos ocupa.

Las crónicas nos informan de la temprana integración de la ciudad de Viseu en el entramado político asturleonés entre los años 866 y 883, junto con otros lugares como Braga, Oporto, Coimbra y Lamego ${ }^{72}$. De todos modos, la existencia de campañas andalusíes previas contra Viseu en los años 825 y 836 probaría la existencia de una población asentada en ese lugar y con algún tipo de estructura política local ${ }^{73}$. Ahora bien, a partir de la integración de Viseu en el territorio político asturiano, la ciudad adquirió cierta importancia, siendo

\footnotetext{
${ }^{71}$ Sobre estos aspectos, véase Moreland 2003.

${ }^{72}$ Albeldense, XV, 12, 15-17; Gil, Moralejo, Ruiz de la Peña 1985.

${ }^{73}$ Ibn Hayyan 2001, 176r-177v, 179v. También existen menciones a dos obispos en Viseu en 770 y 850 , Real 2000 , pp. 45-46.
} 
uno de los principales ejes de la frontera al sur del Duero, sede de un obispado y lugar donde encontramos a algunos miembros de la familia regia, como es el caso de Ramiro II entre 926-930, lo que la convierte en un núcleo relevante en una escala exclusivamente regional ${ }^{74}$. La siguiente fase de integración se produjo bastante tiempo más tarde, en el año 940, tras la batalla de Simancas, cuando el cronista Sampiro nos informa de cómo Ramiro II "pobló" toda la ribera del Tormes, incluyendo una serie de civitates desertas: Salamanca, de la que se nos dice que era sedes antiqua castrorum, Ledesma y otros lugares ${ }^{75}$. El mismo cronista indica a continuación, en el mismo pasaje, que el conde de Castilla Fernán González "pobló” la civitas de Sepúlveda ${ }^{76}$.

Los acontecimientos del año 940 deben ser observados como una fase más de un largo proceso de integración política, una fase caracterizada por la formalización de los lazos políticos entre las poblaciones locales y la autoridad central, que podrían existir previamente. Así se explicarían algunas noticias que hablan de la intervención norteña -cuyo límite sería la ribera del río Duero- en áreas más al sur, tales como la donación de Fruela II del lugar de Katicas, posiblemente en la desembocadura del río Adaja en el Duero, en 92477, o la donación realizada por Fernán González a San Pedro de Arlanza en 937 del monasterio de Santa María de Cárdaba, en las inmediaciones de Sacramenia $^{78}$. Ambos textos probarían la existencia de una influencia de los poderes cristianos en la zona meridional del valle del Duero antes de que se llevara a cabo la formalización de la integración política.

A partir de 940, el nuevo statu quo se plasmó en la formación de una serie de "lugares centrales", donde se hacía presente esa integración y se proyectaba hacia el territorio circundante en forma de "islas de autoridad". Estos pivotes eran grandes centros fortificados como Viseu, Salamanca o Sepúlveda, pero también otros menores como Sacramenia, Portillo o Ledesma. La extensión de las nuevas relaciones políticas hacia las áreas adyacentes no fue uniforme y posiblemente en aquellos puntos que se situaban lejos de estos ganglios apenas se hacía presente la influencia asturleonesa. Así, amplios es-

\footnotetext{
${ }^{74}$ Sáez 1947.

${ }^{75}$ Pérez de Urbel 1952; Sampiro, §23: "Deinde post IIos menses azeiphan, id est exercitus, ad ripam Turmi ire disposuit, et civitates desertas ibidem populauit. Hee sunt: Salamantica sedes antiqua castrorum, Letesma, Ripas, Balneos, Alphandiga, Penna et alia plurima castella quod longe est prenotare".

76 "Populavit Fernando Gunsalviz civitatem que dicitur Septempublica cum Dei auxilio", ibidem.

${ }^{77}$ Ruiz Asencio, Ruiz Albi 2007, doc. 6.

${ }^{78}$ Zabalza 1998, doc. 10. Este documento es considerado falso por el hecho de datarse antes de la repoblación oficial. Pero si aceptamos la existencia previa de una influencia cada vez mayor de los poderes norteños, la fecha no ofrece mayores dificultades.
} 
pacios como el entorno de Ávila o el valle del río Eresma parecen no haber estado integrados formalmente en el reino asturleonés.

Las crónicas andalusíes permiten hacer un poco más densa la geografía de estos "lugares centrales", al menos en una escala menor, gracias a las menciones de las aceifas emprendidas contra este territorio. Así, en 936, se habla del ataque a Trancoso y a una fortaleza no identificada denominada .rb.gueira, que debía estar en sus cercanías ${ }^{79}$. Pero son sobre todo las campañas emprendidas por Almanzor desde 977 las que ofrecen una mayor información. Entre 977 y 989, los ejércitos amiríes atacaron Baños, una de las poblaciones "repobladas" en el valle del Tormes, Cuéllar, Salamanca, al-Mal -probablemente Alba de Tormes-, Sepúlveda, Trancoso, Viseu, Sacramenia y Portillo $^{80}$. Las aceifas amiríes se centraron en los principales "lugares centrales" del poder asturleonés, que pretendía doblegar para que reconociera la hegemonía cordobesa. Por tanto, la nómina sirve para descubrir cuáles eran los núcleos a través de los cuales se hacía patente el dominio asturleonés, algunos de los cuales como Cuéllar, Trancoso o Sacramenia no aparecen en la lista de puntos "poblados" por los reyes.

Por otro lado, la organización de este espacio fue más compleja de lo que las escuetas menciones cronísticas nos permiten vislumbrar. En el año 960, la condesa doña Flámula entregaba una serie de lugares situados entre Trancoso y el río Duero al monasterio de Guimarães:

Ordinamus nostros castellos, id est Trancoso, Moraria, Longobria, Nauman, Vacinata, Amindula, Pena de Dono, Alcobria, Seniorzelli, Caria, cum alias penellas et populaturas que sunt in ipsa Stremadura $^{81}$.

El documento diferencia entre castillos, puntos fuertes de la estructura política, parte de cuyo dominio estaba en manos de la condesa; penellas, probablemente puntos jerárquicos menores procedentes de la organización sociopolítica previa ${ }^{82}$; y populaturas, que podrían ser o bien asentamientos campesinos o aquellos bienes que han sido apropiados por los poderes "repobladores". Todo este conjunto se localiza in Stremadura. Se trata de la primera mención a este corónimo aplicado a espacios del sur del Duero y sería el resultado de la creación de un espacio de frontera. Sin embargo, el corónimo

\footnotetext{
${ }^{79}$ Ibn Hayyan 1981, § 258 .

${ }^{80}$ Molina 1981.

${ }^{81}$ Herculano 1867, doc. LXXXI. Téngase en cuenta que los cuatro castillos citados en primer lugar son Trancoso, Moreira de Rei, Longroiva y Numão.

${ }^{82}$ Se trataría de lugares como São Gens, Penedo dos Mouros, o Queiriz (concelho de Fornos de Algodres), Tente 2009; Marques 2000b, pp. 116, 122.
} 
no vuelve a documentarse en el siglo X, quizá por el fracaso de la política integradora y/o por el hecho de que esta fue aplicada de manera muy desigual en el espacio.

La integración política o "repoblación" se dejó sentir sobre todo en los "lugares centrales", donde se verificaron algunos procesos. Si nos ceñimos a aquellos que son visibles desde las fuentes escritas, uno de los más evidentes fue la construcción de iglesias. En los textos sobre Katicas y Cárdaba ya se ha puesto así de manifiesto, pero resulta aún más evidente en un documento de 953, en el que Ordoño III entregaba al obispo de León las iglesias del alfoz de Salamanca que habían edificado los pobladores procedentes del alfoz de León en tiempos de Ramiro II $^{83}$. Estas iglesias funcionaban como plataformas del prestigio social de sus fundadores y patronos y, mediante ellas, se podían focalizar propiedades y, sobre todo, influencias locales ${ }^{84}$. Su construcción por parte de los repobladores cobra sentido en un ambiente en el que no se atestigua la presencia de centros eclesiásticos, por lo que eran sin duda importantes resortes y marcadores del nuevo dominio social. Por otra parte, el propio texto identifica a algunos de estos repobladores, entre los cuales se encuentran como el obispo Oveco de León, Bermudo Núñez, un importante magnate que fue más adelante conde de Cea y que aparece como conde de Salamanca en $942^{85}$, y Guisvado Braóliz, que aparecería como Iusivado, quien estuvo al frente de la mandación de Luna y fue conde con amplios bienes en Boñar ${ }^{86}$. Resulta evidente que estos pobladores pertenecían a los grupos sociales más elevados del reino asturleonés. En cambio, no hay ninguna noticia acerca de la llegada organizada o espontánea de campesinos desde el norte. Son esos magnates los que vemos obteniendo bienes como consecuencia de la "repoblación", como sucedió con el obispo Oveco en Salamanca en $941^{87}$.

Estos grupos procedentes del entorno leonés van a acumular algunos de los cargos más importantes, al menos por lo que sabemos de la zona de Salamanca. Además de la ya citada mención a Bermudo Núñez como conde de Salamanca en una campaña contra la fortaleza de Saktan en 942, Ibn Hayyan nos informa de que Fernando, hijo del conde de Salamanca, envió a

\footnotetext{
${ }^{83}$ Sáez, Sáez 1990, doc. 260: "Damus adque concedimus post parte domui sancte uestre ecclesias in alhauze de Salamantica, quantas edificaberunt [ibidem pop]ulatores patris mei qui fuerunt de Legione, id est: patri domno Oveco aepiscopo, Iuisiuado, Ueremudus Nunniz, Fortis, Furtunius et Pelagius presbiter uel omnes quantus fuerunt de alhauze de Legione, [tam popula] tores quam qui mandationes abuerunt et fecerunt populationes in ista terra". Puede verse un detallado y excelente análisis de este texto en Mínguez 1997, pp. 32-33.

${ }^{84}$ Pérez 2012.

${ }^{85}$ Ibn Hayyan 1981, § 326; Torres 1998, pp. 99-113.

${ }^{86}$ Mínguez 1997,p. 33.

${ }^{87}$ Sáez 1987, doc. 149.
} 
sus embajadores a al-Hakam II en $971^{88}$. Son estos grupos quienes dominaron las más altas instancias de poder en la Extremadura, incluso en el caso de la corte de Ramiro II en Viseu ${ }^{89}$. En cambio, los grupos locales no recibieron ni bienes, ni altos cargos y, sin embargo, no se documentan resistencias a este dominio. ¿Qué sucedió con estas poblaciones? Carecemos de informaciones fehacientes, pero parece bastante factible que se articulase una relación entre los grupos locales, en especial ciertas elites, y el nuevo poder asturleonés a través de prestaciones militares, como ocurrió en las zonas meridionales del condado de Castilla ${ }^{90}$. En otras zonas de la meseta del Duero se debió generar un mecanismo semejante, que sirvió para formalizar los lazos políticos. Dos indicios parecen avalar esta hipótesis para el caso del sur del Duero. El primero es la importancia de esas prestaciones militares y de la identificación social de las elites con los guerreros a caballo en los fueros posteriores, que tienen uno de sus primeros hitos en el fuero de Sepúlveda de $1076^{91}$. Esa relevancia social de lo guerrero sería consecuencia de la antigua formación de vínculos mediante prestaciones militares y hay que recordar cómo el fuero recoge la tradición de haber sido promulgado en época de Fernán González, lo que, sin ser necesariamente cierto, podría ser un indicio de que esa situación provenía de momentos muy anteriores. El segundo es la actividad militar que se verifica en esos momentos, plasmada en la ya citada campaña de Bermudo Núñez contra Saktan. De todos modos, se ha planteado la posibilidad de que las elites locales se dedicasen desde el siglo VIII a una serie de acciones guerreras de pequeña escala, con el objetivo de obtener botín en un contexto fronterizo ${ }^{92}$. Sin embargo, las referencias a esas acciones son muy tardías, como la mención a los infieles de Riaza que atacaban el tagr de Guadalajara o los prisioneros musulmanes que se hallaban en M.dma (posiblemente Medina del Campo) ${ }^{93}$. Ambas citas son de acontecimientos datados en 939, es decir en un periodo muy tardío, inmediatamente anterior a la "repoblación". Si admitimos la existencia de lazos previos a la formalización que representó la "repoblación", podríamos relacionar esa actividad precisamente con la influencia del poder asturleonés.

Esta militarización habría sido la herramienta principal para hacer efectivas las relaciones entre autoridad central y elites locales, y se habría verificado sobre todo en los "lugares centrales", como Salamanca. Ahora bien, las campañas amiríes, a las que ya se ha hecho referencia, tuvieron

${ }^{88}$ Ibn Hayyan 1967, § 28.

${ }^{89}$ Sáez 1947.

${ }^{90}$ Escalona, Reyes 2011, pp. 175-177.

${ }^{91}$ Gambra 1998, doc. 40. Un magnífico análisis en Monsalvo 2003, pp. 61-66.

${ }^{92}$ Villar 1986, pp. 61-62; Mínguez 2007, p. 205.

${ }^{93}$ Ibn Hayyan 1981, § 294, 299-300. 
como consecuencia la desaparición del poder asturleonés en toda la zona ${ }^{94}$. Salvo en el caso de Viseu, no se produjo la implantación de un poder andalusí directo, e incluso en ese caso parece que se mantuvieron una serie de poderes locales que reconocían la superior potestad de los andalusíes ${ }^{95}$. La destrucción del poder asturleonés provocó que buena parte del territorio quedase de nuevo en una indefinición con respecto a los poderes centrales. Pero las elites situadas en los principales ejes de la región continuaron funcionando. Prueba de ello es la existencia de una inscripción incrustada en una de las torres de las murallas de Sepúlveda y datada en $1063^{96}$. Pero también es un claro indicio el hecho de que varios de estos lugares fueran posteriormente conquistados, como sucedió con Viseu en 1058, o "repoblados" a finales del XI durante el reinado de Alfonso VI y sus sucesores, o durante el periodo de formación de Portugal en la primera mitad del XII. Puede inferirse, por tanto, que la "repoblación" marcó nuevas pautas de identidad y de diferenciación social dentro de las comunidades políticas asentadas o identificadas con esos "lugares centrales".

\section{CRUZANDO DATOS: IDENTIDADES LOCALES EN TRANSFORMACIÓN}

Si cruzamos los datos del registro escrito con los procedentes del mundo funerario, se pone de relieve cómo la mayoría de las necrópolis alineadas se emplazan en esos "lugares centrales", como ocurre con Cuéllar, Ledesma, Longroiva, Moreira de Rei, Numão, Sacramenia, Salamanca, Sepúlveda y Trancoso. Esta tendencia no significa que todos los centros de la integración política del siglo X dispongan de este tipo de necrópolis, pues varios de los lugares citados en la "repoblación" del valle del Tormes ofrecen de momento ese tipo de necrópolis. Y más significativo: de momento no hay evidencias en el caso de Viseu. Aunque es posible que estemos ante un dato distorsionado por las diferencias en el registro arqueológico de cada lugar, parece prudente afirmar que algunos "lugares centrales" no se vinculan con la presencia de necrópolis alineadas, aunque la gran mayoría de los sitios con necrópolis alineadas se asocian a esas "islas de autoridad".

${ }^{94}$ Barrios 1985, pp. 50-51; Mínguez 1997, pp. 38-40.

${ }^{95}$ Aillet 2009.

96 "Era $\mathrm{M}^{\mathrm{a}} \mathrm{C}^{\mathrm{a}} \mathrm{I}$ ista turre fecit re/ ... a magister domini (.) o/... acinidrt[e]vnsemen o", Martín Aymerich, Tardío, Zamora 1990, p. 126. 


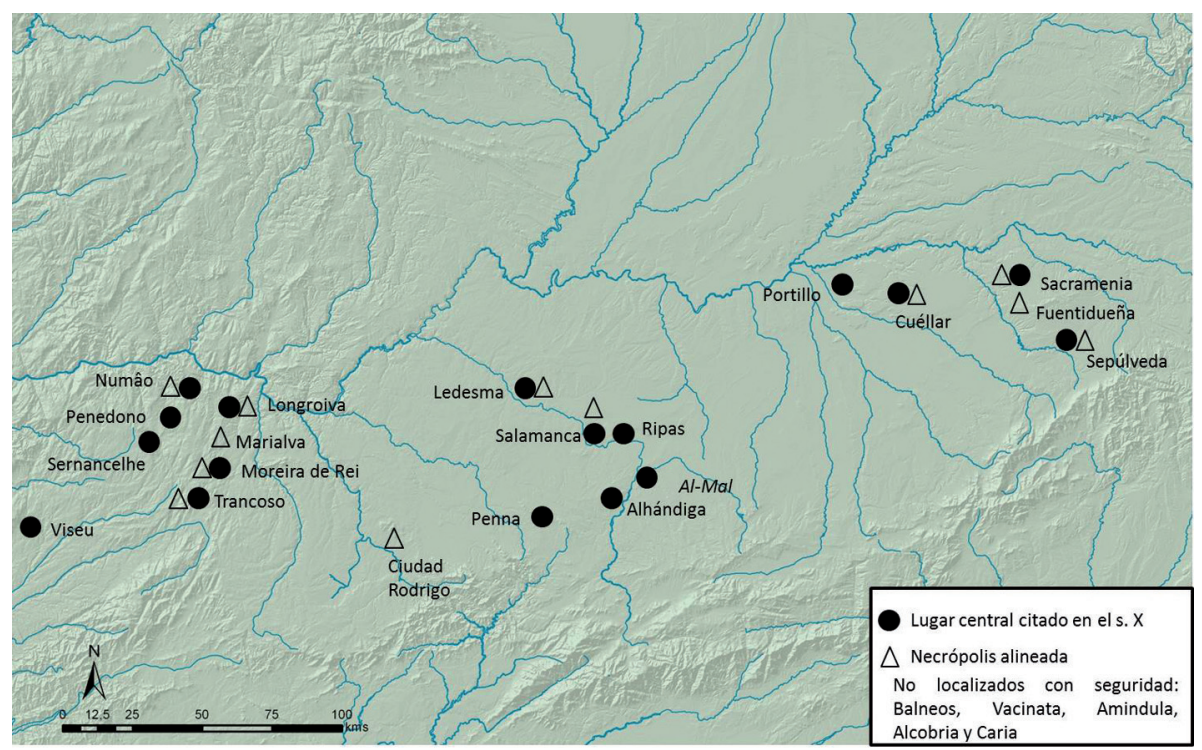

Fig. 9. "Lugares centrales" y necrópolis alineadas en la Extremadura del Duero.

Tres casos, en cambio, rompen esa segunda afirmación: Ciudad Rodrigo, Fuentidueña y Marialva. Ciudad Rodrigo no aparece en las fuentes escritas hasta $1136^{97}$, pero ya entonces parece tener una evidente centralidad en su comarca, que se plasmará en la "repoblación" de $1161^{98}$. Ahora bien, la versión ad Sebastianum de la Crónica de Alfonso III menciona el lugar de Agata entre las civitates despobladas por la acción de Alfonso I y su hermano Fruela a mediados del siglo VIII ${ }^{99}$. Aunque esa cita debe entenderse como una fotografía de la geografía política de la cuenca del Duero a finales del siglo IX desde la perspectiva asturiana, podría ser un indicio del reconocimiento de una cierta preeminencia política, Quizá su jerarquización no se viera reconocida por un poder externo en el siglo $X$, pero esa ausencia de formalización jurídica podría no haber sido obstáculo para ser una comunidad política de cierta relevancia en un ámbito comarcal. Por otro lado, no hay noticias en el registro escrito de Fuentidueña hasta $1135^{100}$, cuando surge como un territorio seguramente jerarquizado por dicho centro. Este lugar se convirtió progresi-

\footnotetext{
${ }^{97}$ Guadalupe et al. 2010, doc. 12.

${ }^{98}$ Barrios 1998.

${ }^{99}$ Sebastianum §13, 8; Gil, Moralejo, Ruiz de la Peña 1985.

${ }^{100}$ Villar 1990, doc. 18.
} 
vamente en un núcleo político comarcal relevante que sustituyó en esa función a Sacramenia durante el siglo XII. Pero parece probable que Fuentidueña hubiera desempeñado algún tipo de centralidad, al menos a lo largo del XI, lo que explicaría que pudiera sustituir a Sacramenia como eje territorial. En cuanto a Marialva, su existencia podría esconderse en alguno de los castillos mencionados en la donación a doña Flámula que no se han podido identificar con claridad, aunque no deja de ser una conjetura. Ahora bien, dada la parquedad de las fuentes escritas para los siglos X y XI en toda la región, pudiera darse la circunstancia de que los tres sitios hubieran funcionado como "lugares centrales", pero no habrían sido mencionados en los escasos textos de los que disponemos.

En cualquier caso, la asociación entre necrópolis alineadas y "lugares centrales" es una tendencia, no una ecuación simple. Sin embargo, las coincidencias, como se ha podido comprobar, son muy elocuentes y las divergencias podrían ser simplemente efecto de las carencias de nuestro registro escrito -no se mencionarían todos los "lugares centrales", esos plurima castella de los que nos habla el cronista Sampiro en la cita sobre la "repoblación" del valle del Tormes- y del registro arqueológico -sobre todo porque muchas de las necrópolis fueron amortizadas por edificios eclesiásticos-. Un aspecto importante es que algunos lugares situados al sur del Sistema Central y que aparecen "repoblados" en el siglo XII, pero que no pueden relacionarse con el proceso de integración política en el reino asturleonés de la décima centuria, poseen necrópolis con tumbas excavadas en la roca, pero pertenecen al tipo de necrópolis desordenadas. Así sucede, por ejemplo, en Monsanto (c. Idanha-a-Nova, Portugal) o en Trevejo (Cáceres), que se mencionan en la segunda mitad del siglo XII como sendos castillos, pero donde se constata la presencia de esas necrópolis desordenadas ${ }^{101}$. Parece, por tanto, que el fenómeno de las necrópolis alineadas se vincula con la integración política del siglo X que se verifica al norte del Sistema Central.

Plantear que estas necrópolis alineadas se vinculan al proceso de integración política no supone, en cambio, considerarlas una mera emanación de los poderes "repobladores". Debe recordarse cómo los documentos escritos recogen la importancia de la construcción de iglesias como un mecanismo para afianzar a los grupos "repobladores". Ninguna de estas necrópolis posee evidencias de la existencia de iglesias asociadas. Este dato, aunque sea negativo, parece ser una huella de que la formación y gestión de estas áreas funerarias no fue una consecuencia directa de la implantación de nuevos pobladores

${ }^{101}$ Azevedo 1958, doc. 315; Ayala 1995, doc. 52. Las necrópolis aparecen referenciadas en Milheiro 1982; García-Figuerola 1990,p. 62. 
o, mejor, de nuevos grupos dirigentes. La hipótesis más factible es que fuesen la emanación de iniciativas de las propias comunidades locales asentadas en esos "lugares centrales" y reconocidas como comunidades políticas. Por tanto, hay que buscar las explicaciones en esas comunidades y en sus transformaciones.

La cronología supone un serio problema que lastra cualquier explicación que podamos dar. Sin embargo, no hay que pensar que todas y cada una de las necrópolis fueran coetáneas, pero, a tenor de los datos que manejamos, podemos hablar de una facies, de un patrón asumido por distintas comunidades, que se expresaría a lo largo de segmento temporal que iría, cuando menos, entre los siglos X, o quizá incluso IX, hasta el XII, seguramente con posibles diferencias entre distintos sitios, aunque de momento no podamos identificarlas. Pueden sostenerse dos posibles explicaciones para estas necrópolis. La primera es que fueran el resultado de las transformaciones que sufrieron las comunidades asentadas en los "lugares centrales" como consecuencia de la integración política en el siglo X. La presencia de lazos con el poder central, el incremento de la militarización y la formación de una identidad relacionada con esos fenómenos podrían ser el origen de la creación de estas necrópolis que son significativamente diferentes de las que se documentan en las áreas rurales, es decir las gestionadas por comunidades que no son "lugares centrales". La segunda es que existieran ya con anterioridad, al menos en algunos lugares, y que fueran la marca de la existencia de comunidades cohesionadas en determinados puntos, lo que motivó la elección de los mismos por los reyes asturleoneses. De momento, resulta imposible saber cuál de las dos es la hipótesis más acertada, más aún si tenemos en cuenta que no conocemos otras áreas funerarias altomedievales en estos lugares, por lo que no somos capaces de vislumbrar si hubo un cambio ${ }^{102}$. Ambas son explicaciones plausibles y no son incompatibles entre sí, pues pueden darse en función de cada lugar.

En cualquier caso, si se tratara de espacios funerarios previos a la "repoblación", probablemente tuvieron que sufrir cambios a lo largo del tiempo. De hecho, la fotografía que tenemos es la de una necrópolis definida, pero eso es el resultado final. Ya se ha advertido que no es un patrón sincrónico, sino un modelo que se constata para un periodo plurisecular, que se abriría en torno a los siglos IX o X. Desde esa perspectiva, puede entenderse que el patrón se extendiera a núcleos que quizá adquirieron entre finales del siglo $\mathrm{X}$ y el primer tercio del siglo XII un papel jerarquizador del que antes carecían, como ocurriría con Fuentidueña, Marialva o Ciudad Rodrigo. Por otro lado,

\footnotetext{
${ }^{102}$ Habría que rechazar la idea de que fueran núcleos vacíos hasta la "repoblación", lo que explicaría la emergencia de nuevas necrópolis. El análisis de la documentación escrita prueba que no era así. Para el caso salmantino, véase Mínguez 1997, p. 30.
} 
los datos sobre reutilizaciones y superposiciones de tumbas serían un indicio del continuo uso de ese espacio funerario a lo largo del tiempo.

Por tanto, puede decirse que las necrópolis alineadas son un fenómeno asociado a los procesos de integración política y de configuración de "lugares centrales" con una identidad propia, en parte consecuencia de la inserción en una escala sociopolítica superior. Pudieron ser anteriores a la "repoblación”, pero los procesos asociados a la integración política configuraron un patrón que se repitió en las principales comunidades políticas de la región. Respondía a los parámetros de dichas comunidades, con una gran cohesión interna y grupos sociales más destacados que en el ámbito rural, generando así una memoria que incluso desde el punto de vista espacial se relacionaba con el "lugar central". Un patrón que puede seguirse incluso en núcleos cercanos, sometidos a una dinámica similar, aunque cronológicamente anterior y quizá con una presencia más directa del poder asturleonés, como Toro (Zamora). En este lugar, emplazado en un espolón sobre el río Duero y que se hallaba dentro del ámbito político asturleonés, se han documentado necrópolis de tumbas en fosa antropomórfica que siguen el mismo patrón de las aquí estudiadas ${ }^{103}$. Pueden inferirse dos conclusiones: por un lado, la repetición de un modelo de espacio funerario asociado a "lugares centrales" de la "repoblación" del siglo X; por otro lado, el hecho de que pueden existir este tipo de necrópolis sin necesidad de la existencia de tumbas excavadas en la roca. La presencia de estas es, sin embargo, un síntoma de la expansión de patrones de inhumación procedentes de espacios y elites rurales, generada a partir del siglo VIII, ya que con anterioridad no se observa la utilización de estas tumbas en centros jerárquicos ${ }^{104}$. En definitiva, las necrópolis de tumbas excavadas en la roca agrupadas y alineadas recogen la herencia de la organización del espacio funerario propia de los "lugares centrales" desde el momento postromano, pero suman la monumentalidad propia de las sepulturas excavadas en la roca de ámbito rural.

La importancia de estos "lugares de memoria" de las comunidades situadas en los "lugares centrales" explica su evolución posterior, con la implantación de iglesias parroquiales que amortizaron esos espacios funerarios. La Iglesia fue uno de los principales mecanismos de encuadramiento de las sociedades extremaduranas desde finales del siglo XI, junto con la creación de los sistemas concejiles ${ }^{105}$. Pero la red eclesiástica suponía toda una innovación

\footnotetext{
${ }^{103}$ Salvador et al. 1994; Salvador, Viñé 1998.

${ }^{104}$ Es el caso de los centros fortificados o castella, como Las Merchanas (Lumbrales, Salamanca) o La Cabeza de Navasangil (Solosancho, Ávila), Maluquer 1968; Caballero, Peñas 2012, pp. 219-222.

${ }^{105}$ Villar 1986; Barrios 2000, pp. 379-390.
} 
en el paisaje social hasta el siglo XIII. Esa red comenzó a formarse en los núcleos concejiles, buena parte de los cuales habían sido los "lugares centrales" del siglo X. Estamos además en un momento en el que en toda Europa Occidental se está produciendo la configuración del cementerio parroquial, un espacio funerario sacralizado y diferenciado del edificio eclesiástico, aunque situado junto a él. A partir de ese momento, la identidad parroquial jugó un papel destacado en las identidades individuales y grupales.

Este modelo comienza a imponerse en la Extremadura del Duero a partir de los "lugares centrales". Buen ejemplo de ello es que en 1089, el conde Martín Alfonso donaba a San Zoilo de Carrión el monasterio de Santa María de Íscar con la iglesia y el cementerio anejos, es decir poco después de la "repoblación" de este lugar en época de Alfonso VI ${ }^{106}$. Ese proceso explica que parte de las parroquias de las villas plenomedievales se levantaran sobre áreas funerarias previas. El objetivo era aprovechar ciertos espacios considerados sagrados, que desempeñaban un papel esencial en la identidad comunitaria. La evolución fue en ocasiones muy rápida, como se constata en la iglesia de Santiago (Sepúlveda), pero en otros casos debió dilatarse en el tiempo, por lo que nos podemos encontrar con un uso tardío de la necrópolis. En cualquier caso, ese fenómeno de amortización es general, lo que no debe extrañarnos, pues muchos de estos lugares se convirtieron en sedes episcopales o en cabezas de arcedianatos y arciprestazgos, es decir los ganglios desde los que se extendió la red parroquial sobre el territorio. En definitiva, la Iglesia se apropió y modificó esos "lugares de memoria" en un proceso que duró años o decenios. El resultado fue un cambio fundamental en uno de los elementos básicos de la identidad de esas comunidades locales, cuyos miembros ahora se sentían parte de una parroquia, en cuyos alrededores surge un cementerio, gestionado por la Iglesia y no por la comunidad.

\section{BIBLIOGRAFÍA CITADA}

Aillet, Cyrile (2009), El monasterio de Lorvão y los confines de la Beira (siglos IX-XII). Apuntes sobre la memoria histórica de un espacio de contacto, "Studia Historica. Historia Medieval" 27, pp. 71-95.

Ajamil, Francisco Javier (2012), Resultados de la intervención arqueológica en la plaza María Díez de Ure de Treviño. La confirmación de la ocupación de este espacio desde, al menos, el siglo XI, en González de Viñaspre, Roberto; Garay, Ricardo (eds.), Viaje a Íbita. Estudios his-

${ }^{106}$ Pérez Celada 1986, doc. 11.

ANUARIO DE Estudios MEDIEVALES, 46/2, julio-diciembre 2016, pp. 859-898 ISSN 0066-5061, doi:10.3989/aem.2016.46.2.09 
tóricos del Condado de Treviño, Treviño, Ayuntamiento de Treviño, pp. 415-425.

Alacet Arqueólogos (2006), Excavaciones arqueológicas previas en la iglesia de Santa Elena de Ledesma (Salamanca), Valladolid (informe inédito).

Almeida, Carlos; Antunes, João; Faria, Pedro (2000), Sinais do passado em Marialva, concelho de Meda, "Douro. Estudos \& Documentos" 10, pp. 173-218.

Amaral, María Antónia (2001), A necrópole de São Pedro de Marialva. Estudo arqueológico, "Património e Estudos" 1, pp. 129-138.

Andrio, Josefa (1994), Dos necrópolis medievales. Quintana María y Cuyacabras (Burgos), "Boletín de Arqueología Medieval" 8, pp. 163-188.

Antunes, João; Faria, Pedro; Almeida, Carlos Brochado de (1998), Aspectos da história Antiga de Longroiva, "Douro. Estudos \& Documentos" 6, pp. 241-248.

Aratikos Arqueólogos (2005), Intervención arqueológica en la iglesia de San Esteban. Cuéllar (Segovia), Burgos (informe inédito).

Aratikos Arqueólogos (2008), Informe técnico. Excavación y prospección arqueológica en la iglesia de San Miguel de Sacramenia (Segovia), Valladolid (informe inédito).

Arias, Javier (1993), Necrópolis medieval de San Andrés (Cuéllar, Segovia), "Numantia" 4, pp. 229-238.

Arroyo Pardo, Eduardo, et al. (2011), La iglesia de San Esteban de Cuéllar, Valladolid, Fundación del Patrimonio Histórico de Castilla y León.

Ayala, Carlos de (1995), Libro de privilegios de la Orden de San Juan de Jerusalén en Castilla y León (siglos XII-XV), Madrid, Universidad Complutense.

Azevedo, Rui Pinto de (ed.) (1958), Documentos medievais portugueses. Documentos régios. Volume I. Documentos dos condes portugalenses e de D. Afonso Henriques. A. D. 1095-1185, Lisboa, Academia Portuguesa da História.

Barrios, Ángel (1983-1984), Estructuras agrarias y de poder en Castilla. El ejemplo de Ávila (1085-1320), Salamanca, Institución Gran Duque de Alba.

Barrios, Ángel (1985), Repoblación de la zona meridional del Duero. Fases de ocupación, procedencias y distribución espacial de los grupos repobladores, "Studia Historica. Historia Medieval" 3/2, pp. 33-82.

Barrios, Ángel (1998), El proceso de ocupación y de ordenación del espacio en la raya leonesa, en Braga Cruz, Manuel (coord.), O Tratado de 
Alcanices e a importãncia histórica das terras de Riba Côa, Lisboa, Universidade Católica, pp. 155-183.

Barrios, Ángel (2000), Colonización y feudalización: el desarrollo de la organización concejil y diocesana y la consolidación de las desigualdades sociales, en Barrios, Ángel (coord.) Historia de Ávila II. Edad Media (siglos VIII-XIII), Ávila, Institución Gran Duque de Alba, pp. 337-410.

Barroca, Mário J. (1987), Necrópoles e sepulturas medievais de Entre-oDouro-e-Minho (séculos V a XV), Oporto, s.n.

Benavente, José Antonio; Paz, Juan Ángel; Ortiz, Esperanza (2006), De la Antigüedad tardía hasta la conquista cristiana em el Bajo Aragón, en Sénac, Philippe (ed.), De la Tarraconaise à la Marche Supériure d'alAndalus (IVe-XIesiècle): les habitats ruraux, Toulouse, Publications du Mirail, pp. 99-119.

Bielsa, María Asunción (1977), Tipología de las tumbas antropomorfas de la zona aragonesa al norte del Ebro, en XIV Congreso Nacional de Arqueología, Zaragoza, Secretaría General de los Congresos Arqueológicos Nacionales, pp. 1235-1240.

Blanco González, Antonio; López Sáez, José Antonio; López Merino, Lourdes (2009), Ocupación y uso del territorio en el sector centromeridional de la cuenca del Duero entre la Antigüedad y la Alta Edad Media (siglos I-XI d.C.), "Archivo Español de Arqueología" 82, pp. 275-300.

Blaizot, Frédérique (2006), Ensembles funéraires isoles dans la moyenne vallée du Rhône, en Maufras, Odile (ed.), Hábitats, nécropoles et paysages dans la moyenne et la base vallée du Rhône (VIIeXVe s.), París, Éditions de la Maison des sciences de l'homme, pp. 281-362.

Caballero, Jesús; Peñas, David (2012), Un castrum de época visigoda en el valle Amblés: La Cabeza de Navasangil (Solosancho, Ávila), en Quirós, Juan Antonio; Tejado, José María (eds.), Los castillos altomedievales en el Noroeste de la Península Ibérica, Bilbao, Universidad del País Vasco, pp. 213-238.

Castillo, Alberto del (1970), Cronología de las tumbas llamadas olerdolanas, en XI Congreso Nacional de Arqueología, Zaragoza, Secretaria General de los Congresos Arqueológicos Nacionales, pp. 835-845.

Castillo, Alberto del (1972), Excavaciones altomedievales en las provincias de Soria, Logroño y Burgos, Madrid, Comisaría General de Excavaciones Arqueológicas.

Coixão, António (1999), Rituais e cultos da morte na região de entre Douro e Côa, Freixo de Numão, ACDR - Freixo de Numão. 
Collardelle, Michel; Démians d'Archimbaud, Gabrielle; Raynaud, Claude (1996), Typo-chronologie des sépultures du Bas-Empire à la fin du Moyen Âge dans le Sud-Est de la Gaule, en Galinié, Henri; ZadoraRio, Elizabeth (eds.), Archéologie du cimetière chrétien. Actes du $2 e$ colloque ARCHEA, Tours, Feracf, pp. 271-304.

Cunha, Eugénia; Umbelino, Cláudia; Tavares, Teresa (2001), A necrópole de São Pedro de Marialva. Dados antropológicos, "Património e Estudos" 1, pp. 138-143.

David, Bruno; Thomas, Julian (2008), Landscape archaeology: introduction, en David, Bruno; Thomas, Julian (coords.), Handbook of landscape archaeology, Walnut Creek, Left Coast Press, pp. 27-45.

Devlin, Zoe (2007), Remembering the dead in anglo-saxon England. Memory theory in archaeology and history, Oxford, British Archaeological Reports.

Domenech, Manuela (1994), Excavaciones arqueológicas en la necrópolis rupestre de Tiermes. Campañas de 1981 y 1982, en Casa Martínez, Carlos de la (coord.), Tiermes III. Excavaciones realizadas en la ciudad romana y en las necrópolis medievales (campañas de 19811984), Madrid, Instituto de Conservación y Restauración de Bienes Culturales, pp. 63-81.

Dordio, Paulo (1998), Centros de povoamento: um percurso pelas vilas medievais, en Lima, Alexandra (coord.), Terras do Côa. Da Malcata ao Reboredo. Os valores do Côa, Guarda, Parque Arqueológico do Vale do Côa, pp. 14-73.

Durand, Marc (1988), Archéologie du cimetière médiéval au Sud-Est de l'Oise. Relations avec l'habitat et évolution des rites et des pratiques funéraires du VIème au XVIème siècle, Amiens, Revue Archeologique de Picardie.

Escalona, Julio (2010), Territorialidad e identidades locales en la Castilla condal, en Jara, José Antonio; Martin, Georges; Alfonso, Isabel (eds.), Construir la identidad en la Edad Media, Cuenca, Universidad de Castilla-La Mancha, pp. 55-82.

Escalona, Julio; Reyes, Francisco (2011), Scale change on the border: the county of Castile in the tenth century, en Escalona, Julio; Reynolds, Andrew (eds.), Scale and scale change in the early Middle Ages. Exploring landscape, local society and the world beyond, Turnhout, Brepols, pp. 153-183.

Fabián, Juan Francisco; Santonja, Manuel; Fernández Moyano, Antonio; Benet, Nicolás (1986), Los poblados visigodos de "Cañal”, Pelayos (Salamanca). Consideraciones sobre el poblamiento entre los siglos $V$ y VIII en el SE de la provincia de Salamanca, en I Congreso de 
Arqueología Medieval Española, Zaragoza, Diputación General de Aragón, vol. II, pp. 187-202.

Fentress, James; Wickham, Chris (2003), Memoria social, Valencia, Universidad de Valencia.

Ferreira, María Ceu (2000), Contributos para a carta arqueológica do concelho de Trancoso, en Beira interior. História e Património, Guarda, Câmara Municipal da Guarda, pp. 361-374.

Fortó García, Abel; Maese Fidalgo, Xavier; Vidal Sánchez, Álex (2012), Les necrópolis andorranes de L'Hort de l'Esglesia (La Massana), del Camp del Perot i del Camp Vermell (Sant Julià de Lòria), en Molist, Núria; Ripoll, Gisela (eds.), Arqueologia funeraria al nord-est peninsular (segles VIXII), Barcelona, Museu d'Arqueologia de Barcelona, vol. 1, pp. 221-235

Gambra, Andrés (1998), Alfonso VI: cancillería, curia e imperio, León, Centro de Estudios San Isidoro.

García-Figuerola, Miguel (1999), Arqueología romana y altomedieval de la Sierra de Gata (El valle de Valverde. Provincia de Cáceres), Cáceres, Universidad de Extremadura.

Gil Fernández, Juan; Moralejo, José Luis; Ruiz de la Peña, Jose Ignacio (eds.) (1985), Crónicas asturianas, Oviedo, Universidad de Oviedo.

Golvano, María Ángeles (1977), Necrópolis altomedieval de Fuentidueña (Segovia). Julio 1972 y Julio 1973, "Noticiario Arqueológico Hispánico. Arqueología" 5, pp. 359-365.

González Echegaray, Joaquín (coord.) (2000), El Colegio de la Compañía de Jesús en Salamanca (Universidad Pontificia). Arqueología e Historia, Salamanca, Universidad Pontificia de Salamanca.

Guadalupe Beraza, María Luisa; Martín, José Luis; Vaca, Ángel; Villar, Luis Miguel (2010), Colección documental del archivo de la catedral de Salamanca, I (1098-1300), León, Centro de Estudios San Isidoro.

Gutiérrez Dohijo, Eusebio (2001), ¿Dos necrópolis entre la Antigüedad y el Medievo? El Quintanar de Montejo de Tiermes y la rupestre de Tiermes (Soria), en V Congreso de Arqueología Medieval Española, Valladolid, Junta de Castilla y León, vol. I, pp. 115-123.

Gutiérrez Lloret, Sonia; Cánovas, Pablo (2009), Construyendo el siglo VII: arquitecturas y sistemas constructivos en el Tolmo de Minateda, en Caballero, Luis; Mateos, Pedro; Utrero, María Ángeles (eds.), El siglo VII frente al siglo VII, Madrid, CSIC, pp. 91-132.

Hamerow, Helen (2012), Rural settlements and society in anglo-saxon England, Oxford, Oxford University Press.

Härke, Heinrich (2001), Cemeteries as places of power, en De Jong, Mayke; Theuws, Frans; Van Rhijn, Carine (eds.), Topographies of power in the early Middle Ages, Leiden, Brill, pp. 9-30. 
Herculano, Alexandre (ed.) (1867), Portugaliae Monumenta Historica. Diplomata et chartae, Lisboa, Academia das Ciências.

Hooke, Della (1997), The Anglo-Saxons in England in the seventh and eighth centuries: aspects of location in space, en Hines, John (ed.), The anglo-saxons from the migration period to the eighth century. An ethnographic perspective, Woodbridge, The Boydell Press, pp. 65-85.

Ibn Hayyan (1967), El califato de Córdoba en el Muqtabis de Ibn Hayyan. Anales palatinos del califa de Córdoba al-Hakam II, por 'İsa ibn Ahmad al-Rāzi (360-364 H.=971-975 J.C.), ed. Emilio García Gómez, Madrid, Sociedad de Estudios y Publicaciones.

Ibn Hayyan (1981), Crónica del califa 'Abdarrahman III an-Nasir entre los años 912 y 942 (al-Muqtabis V), eds. María Jesús Viguera, Federico Corriente, José María Lacarra, Zaragoza, Anubar.

Ibn Hayyan (2001), Crónica de los emires Alhakam I y Abdarrahman II entre los años 796 y 847, eds. Mahmud Ali Makki, Federico Corriente, Zaragoza, Universidad de Zaragoza.

Izquierdo, José Ma (1977), Excavaciones en las Vegas de Pedraza, Santiuste de Pedraza (Segovia), 1972-1973, "Noticiario Arqueológico Hispánico. Arqueología" 5, pp. 303-311.

Jiménez, Miguel; Mattei, Lucca; Ruiz Jiménez, Ana (2011), Rituales y espacios funerario en la Alta Edad Media: las necrópolis excavadas en la roca de Martilla y Tózar (Granada), en Jiménez, Miguel; GarcíaContreras, Guillermo (eds.), Paisajes históricos y arqueología medieval, Granada, Alhaulia, pp. 141-175.

Knapp, Arthur Bernard; Ashmore, Wendy (2000), Archaeological landscapes: constructed, conceptualized, ideational, en Knapp, Arthur Bernard; Ashmore, Wendy (eds.), Archaeologies of landscape. Contemporary perspectives, Cambridge, Cambridge University Press, pp. 1-30.

La Rocca, Cristina (1989), Donare, distribuire, spezzare. Pratiche di conservazione della memoria e dello status in Italia tra VIII e IX secolo, en Brogiolo, Gian Pietro; Cantino Wataghin, Gisella (eds.), Sepolture tra IV e VIII secolo, Mantua, Società Archeologica Padana, pp. 77-87.

Laliena, Carlos; Ortega, Julián (2005), Arqueología y poblamiento. La cuenca del río Martín en los siglos V-VIII, Zaragoza, Universidad de Zaragoza.

Larrén, Hortensia; Gutiérrez González, José Avelino (1999), Recinto amurallado de Ciudad Rodrigo, en II Congreso de Arqueología Peninsular, Zamora, Fundación Alfonso Henriques, vol. 4, pp. 497-506.

Lauwers, Michel (2005), Naissance du cimetière. Lieux sacrés et terres des morts dans l'Occident medieval, París, Aubier. 
Lopes, Alexandra, Valente, Heloisa; Barreira, Paula (1998): Vila Velha de Numão, um projecto de investigação arqueológica em curso, en Lima, Alexandra (coord.), Terras do Côa. Da Malcata ao Reboredo. Os valores do Côa, Guarda, Parque Arqueológico do Vale do Côa, pp. 24-29.

López Quiroga, Jorge (2010), Arqueología del mundo funerario en la Península Ibérica (siglos V-X), Madrid, La Ergástula.

Lourenço, Sandra (2007), O povoamento alto-medieval entre os rios Dão e Alva, Lisboa, Instituto Português de Arqueologia.

Loyola, Esther (1977), Nuevas aportaciones al estudio de la arqueología altomedieval en las provincias de Logroño y Burgos, en XIV Congreso Nacional de Arqueología, Zaragoza, Secretaría General de los Congresos Nacionales de Arqueología, pp. 1227-1230.

Maluquer, Juan (1968), Excavaciones arqueológicas en el castro de "Las Merchanas" (Lumbrales, Salamanca), "Pyrenae" 4, pp. 101-128.

Marques, Jorge Adolfo (2000a), Sepulturas escavadas na rocha na região de Viseu, Viseu, s.n.

Marques, Jorge Adolfo (2000b), Castelos da reconquista na região de Viseu, em $3^{\circ}$ Congresso de Arqueológia Peninsular, Oporto, ADECAP, vol. 7, pp. 113-129.

Martín Aymerich, María Dolores; Tardío, Teresa; Zamora, Alonso (1990), Las murallas de Sepúlveda (Segovia). Un ensayo de aproximación con métodos arqueológicos a un ejemplo de pervivencia arquitectónica, Segovia, Diputación Provincial de Segovia.

Martín Viso, Iñaki (2007), Tumbas y sociedades locales en el centro de la Península Ibérica en la Alta Edad Media: el caso de la comarca de Riba Côa (Portugal), "Arqueología y Territorio Medieval" 14, pp. 21-47.

Martín Viso, Iñaki (2009), Espacios sin Estado: los territorios occidentales entre el Duero y el Sistema Central (siglos VIII-IX), en Martín Viso, Iñaki (ed.), ¿Tiempos oscuros? Territorio y sociedad en el centro de la Península Ibérica (siglos VII-XI), Madrid, Sílex, pp. 107-135.

Martín Viso, Iñaki (2011), La organización social de los espacios funerarios altomedievales en los territorios al sur del Duero, en Varela, Mário; Varela, Rosa; Tente, Catarina (eds.), Cristãos e Muçulmanos na Idade Média Peninsular. Encontros e Desencontros, Lisboa, Instituto de Arqueologia e Paleociências, pp. 225-238.

Martín Viso, Iñaki, (2012a), Paisajes sagrados, paisajes eclesiásticos. De la necrópolis a la parroquia en el centro de la Península Ibérica, "Reti Medievali. Rivista” 12/2, pp. 3-45. 
Martín Viso, Iñaki (2012b), Enterramientos, memoria social y paisaje en la Alta Edad Media: propuestas para un análisis de las tumbas excavadas en roca en el centro-oeste de la Península Ibérica, "Zephyrus" 68, pp. 165-187.

Martín Viso, Iñaki; Rubio Díez, Rubén (2013), Informe técnico: primera campaña de excavación arqueológica en el yacimiento de La Genestosa (Casillas de Flores, Salamanca), Salamanca (informe inédito).

Milheiro, María (1982), Monsanto. História e arqueologia, Oporto, s.n.

Mínguez, José María (1997), La repoblación de los territorios salmantinos, en Mínguez, José María (coord.), Historia de Salamanca, II. Edad Media, Salamanca, Centro de Estudios Salamantinos, pp. 13-74.

Mínguez, José María (2007), La frontera del Sistema Central: una realidad difusa, en Ser Quijano, Gregorio del; Martín Viso, Iñaki (eds.), Espacios de poder y formas sociales en la Edad Media. Estudios dedicados a Ángel Barrios, Salamanca, Universidad de Salamanca, pp. 203-218.

Molina, Luis (1981), Las campañas de Almanzor a la luz de un nuevo texto, "Al-Qantara" 2, pp. 231-232.

Molist, Núria; Bosch, Josep Maria (2012), El cementiri medieval de Sant Miquel d'Olèrdola (Olèrdola, Alt Penedès), en Molist, Núria; Ripoll, Gisela (eds.), Arqueologia funeraria al nord-est peninsular (segles VI-XII), Barcelona, Museu d'Arqueologia de Barcelona, vol. 2, pp. 469-494.

Monsalvo, José María (1992), Concejos castellano-leoneses y feudalismo (siglos XI-XIII). Reflexiones para un estado de la cuestión, "Studia Historica. Historia Medieval” 10, pp. 203-243.

Monsalvo, José María (2003), Frontera pionera, monarquía en expansión y formación de los concejos de villa y tierra. Relaciones de poder en el realengo concejil entre el Duero y el Tajo (c. 1072-c. 1222), "Arqueología y Territorio Medieval" 10/2, pp. 45-126.

Mora-Figueroa, Luis de (1981), La necrópolis hispanovisigoda de Sanlucarejo (Arcos de la Frontera, Cádiz), "Estudios de Historia y Arqueología Medievales" 1, pp. 63-76.

Moreland, John (2003), Archaeology and text, Londres, Duckworth.

Ollich, Imma (2012), La necrópolis medieval de L'Esquerda (segles VIII-XIV d.C.). Cronologia i noves perspectives de recerca, en Molist, Núria; Ripoll, Gisela (eds.), Arqueologia funeraria al nord-est peninsular (segles VI-XII), Barcelona, Museu d'Arqueologia de Barcelona, vol.2, pp. 275-286.

Padilla, José Ignacio (2002), Yacimiento arqueológico de Cuyacabras. Despoblado, iglesia y necrópolis. Eremitorio de Cueva Andrés. 
Quintanar de la Sierra (Burgos), Barcelona, Universidad de Barcelona.

Padilla, José Ignacio; Álvaro, Karen (2010), Necrópolis rupestres y el poblamiento altomedieval en el alto Arlanza (Burgos), "En la España Medieval" 33, pp. 259-294.

Padilla, José Ignacio; Álvaro, Karen (2012), Alberto del Castillo y la cronología de las tumbas llamadas "olerdolanas", en Molist, Núria; Ripoll, Gisela (eds.), Arqueologia funeraria al nord-est peninsular (segles VIXII), Barcelona, Museu d'Arqueologia de Barcelona, vol. I, pp. 33-40.

Parker Pearson, Michael (1999), The archaeology of death and burial, Stroud, Sutton.

Pecqueur, Laure (2003), Des morts chez les vivants. Les inhumations dans les habitats ruraux du Haut Moyen Âge en Île-de-France, "Archéologie Médiévale" 33, pp. 1-31.

Pérez, Mariel (2012), El control de lo sagrado como instrumento de poder: los monasterios particulares de la aristocracia altomedieval leone$s a$, "Anuario de Estudios Medievales" 42/2, pp. 799-822.

Pérez Celada, Julio (1986), Documentación del monasterio de San Zoilo de Carrión (1047-1300), Palencia, Garrido Garrido.

Pérez de Urbel, Justo (ed.), Sampiro. Su crónica y la monarquía leonesa en el siglo X, Madrid, CSIC, 1952.

Real, Manuel (2000), Portugal: cultura visigoda e cultura moçarabe, en Caballero, Luis; Mateos, Pedro (eds.), Visigodos y omeyas. Un debate entre la Antigüedad Tardía y la Alta Edad Media, Madrid, CSIC, pp. 21-75.

Roig, Jordi; Coll, Joan Manel (2012), El mon funerari dels territoria de Barcino $i$ Egara entre l'Antiguitat tardana i l'època altmedieval (segles V al XII): caracteritzaciò de les necrópolis i cronotipologia de les sepultures, en Molist, Núria; Ripoll, Gisela (eds.), Arqueologia funeraria al nord-est peninsular (segles VI-XII), Barcelona, Museu d'Arqueologia de Barcelona, vol. 2, pp. 373-401.

Rubio, Rubén (2011), Los sepulcros rupestres del suroeste salmantino: mundo funerario y poblamiento entre la tardoantigüedad y la Alta Edad Media, Salamanca, Universidad de Salamanca (trabajo de grado inédito).

Ruiz Asencio, José Manuel; Ruiz Albi, Irene (2007), Colección documental del Monasterio de San Pedro de Eslonza, León, Centro de Estudios San Isidoro.

Ruiz Cecilia, José Ildefonso; Román, Julio (2005), Aproximación a la cronología de la necrópolis rupestre de Las Cuevas (Osuna, Sevilla): las cuevas 5 y 6, "Spal" 14, pp. 231-258.

ANUARIO DE Estudios MEdievales, 46/2, julio-diciembre 2016, pp. 859-898

ISSN 0066-5061, doi:10.3989/aem.2016.46.2.09 
Ruiz Montejo, Inés (1988), El románico de villas y tierras de Segovia, Madrid, Encuentro.

Sáez, Carlos; Sáez, Emilio (1990), Colección documental del archivo de la catedral de León. II (953-985), León, Centro de Estudios San Isidoro.

Sáez, Emilio (1947), Ramiro II, rey de "Portugal" de 926 a 930, "Revista Portuguesa de História” 3, pp. 271-290.

Sáez, Emilio (1987), Colección documental del archivo de la catedral de León. I (775-952), León, Centro de Estudios San Isidoro.

Salvador, Mónica; Viñé, Ana I. (1998), Documentación arqueológica de la iglesia de San Lorenzo el Real de Toro. Zamora, "Anuario del Instituto de Estudios Zamoranos Florián de Ocampo" 15, pp. 73-85.

Salvador, Mónica; Iglesias del Castillo, Luis; Martín Arija, Ana María; Viñé, Ana I. (1994), Excavación arqueológica en la iglesia de San Salvador de los Caballeros. Toro. Futuro Museo de Arte Sacro de la ciudad, "Anuario del Instituto de Estudios Zamoranos Florián de Ocampo" 14, pp. 93-108.

Sánchez-Albornoz, Claudio (1966), Despoblación y repoblación del valle del Duero, Buenos Aires, Instituto de Historia de España.

Serrano, José Luis; Castillo, Juan Carlos (2000), Las necrópolis medievales de Marroquíes Bajos (Jaén). Avance de las investigaciones arqueológicas, "Arqueología y Territorio Medieval" 7, pp. 93-120.

Tente, Catarina (2007), A ocupação alto-medieval da encosta noroeste da Serra da Estrela, Lisboa, Instituto Português de Arqueologia.

Tente, Catarina (2009), Viver em autarcia. A organização do território do alto Mondego (Portugal) entre os séculos $V$ a $X$, en Martín Viso, Iñaki (ed.). ¿Tiempos oscuros? Territorio y sociedad en el centro de la Península Ibérica (siglos VII-XI), Madrid, Sílex, pp. 137-157.

Tente, Catarina (2010), Arqueologia medieval cristã no Alto Mondego. Ocupação e exploração do território nos séculos V a XI, Lisboa, Universidade Nova de Lisboa, 2010 (tesis doctoral).

Tente, Catarina (2011), Do século IX ao XI no Alto Vale do Mondego (Guarda, Portugal): dinâmicas do povoamento e estruturas sociais, "Debates de Arqueología Medieval" 1, pp. 23-43.

Tente, Catarina; Carvalho, António F. (2011), The establishment of radiocarbon chronologies for early medieval sites: a case of study from Upper Mondego valley (Guarda, Portugal), "Munibe" 62, pp. 461-468.

Torres, Margarita (1998), El reino de León en el siglo X: el condado de Cea, León, Universidad de León.

Treffort, Cécile (1996), L’Église caroligienne et la mort. Christianisme, rites funéraires et pratiques commémoratives, Lyon, Presses Universitaires de Lyon. 
Van Dyke, Ruth M.; Alcock, Susan E. (2003), Archaeologies of memory: an introduction, en Van Dyke, Ruth M.; Alcock, Susan E. (eds.), Archaeologies of memory, Oxford, Blackwell Publishing, pp. 1-13.

Varela, Mário (2002), A necrópole visigótica do Poço dos Mouros (Silves), "Revista Portuguesa de Arqueologia" 5/2, pp. 339-391.

Vieira, Marina Afonso (2004), Alto Paiva. Povoamento nas épocas romana e alto-medieval, Lisboa, Instituto Português de Arqueologia.

Villar, Luis Miguel (1986), La Extremadura castellano-leonesa. Guerreros, clérigos y campesinos (711-1252), Valladolid, Junta de Castilla y León.

Villar, Luis Miguel (1990), Documentación medieval de la catedral de Segovia (1115-1300), Salamanca, Universidad de Salamanca.

Viñé, Ana I.; Larrén, Hortensia (1996), Una iglesia mudéjar en Ciudad Rodrigo (Salamanca) y su contexto histórico, "Numantia" 6, pp. 173-186.

Williams, Howard (2003), Introduction. The archaeology of death, memory and material culture, en Williams, Howard (ed.), Archaeologies of remembrance. Death and memory in past societies, Nueva York, Kluver, pp. 1-23.

Williams, Howard (2006), Death and memory in early medieval Britain, Cambridge, Cambridge University Press.

Zabalza, Manuel (1998), Colección diplomática de los condes de Castilla, Salamanca, Junta de Castilla y León.

Zadora-Rio, Elisabeth (2003), The making of churchyards and parish territories in the early medieval landscape of France and England in the 7th-12th centuries: a reconsideration, "Medieval Archaeology" 47, pp. 1-19.

Zadora-Rio, Elisabeth (2005), L'historiographie des paroisses rurales à l'épreuve de l'archeologie, en Delaplace, Christine (ed.), Aux origines de la paroisse rurale en Gaule méridionale (IVe-IXe siècles), París, Errance, 2005, pp. 15-23.

Fecha de recepción del artículo: julio 2013

Fecha de aceptación y versión final: marzo 2014 